ISSN: 0514-7336

DOI: https://doi.org/10.14201/zephyrus2017793961

\title{
'BIOGRAFÍA' DE UN MONUMENTO MEGALÍTICO: FASES DE USO Y CLAUSURA EN EL DOLMEN DE EL TERIÑUELO (ALDEAVIEJA DE TORMES, SALAMANCA)
}

\section{'Biography' of a Megalithic monument: phases of use and closure at the passage grave of El Teriñuelo (Aldeavieja de Tormes, Salamanca)}

Cristina Tejedor Rodríguez*, Manuel A. Rojo Guerra**, Rafael Garrido Pena**, Íñigo García Martínez de Lagrán* y Ángel L. Palomino Lázaro****

* Instituto Arcadia. Fundación General de la Univ. de Valladolid. Residencia Universitaria Alfonso VIII. C/ Real de Burgos, s/n. 47011 Valladolid.Correo-e: tejedor.cristina@gmail.com; igmtzl@gmail.com

** Dpto. Prehistoria y Arqueología. Facultad de Filosofía y Letras-UvA. Plaza del Campus, s/n. 47011 Valladolid. Correo-e:marojo@fyl.uva.es

*** Dpto. Prehistoria y Arqueología. Facultad de Filosofía y Letras-UAM. Carretera de Colmenar Viejo, km 15. Cantoblanco.28049 Madrid. Correo-e: rafael.garrido@uam.es

****Aratikos-Arqueólogos, SL. C/ Estación, 37. 47004 Valladolid. Correo-e: angel@aratikos.com

Recepción: 3/05/2016; Revisión: 23/07/2016; Aceptación: 22/03/2017

Resumen: El dolmen de El Terińuelo, ubicado en el municipio de Aldeavieja de Tormes, forma parte de uno de los focos megalíticos más nutridos y mejor documentados de la provincia de Salamanca. Este sepulcro de corredor ha sido objeto de numerosas intervenciones arqueológicas que, desde fechas anteriores a 1930, han ido desgranando partes de su historia. Los resultados de la última campaña de excavación, que fue llevada a cabo por los firmantes de este artículo en 2005, han permitido completar su secuencia de utilización, gracias al hallazgo de nuevas evidencias de su uso y, en particular, de su clausura. A lo largo de este trabajo, se presentarán las distintas manifestaciones arqueológicas de este singular evento ritual, dentro del contexto de las distintas fases de ocupación del dolmen y partiendo de un enfoque biográfico que permita mostrar la compleja sucesión de prácticas que se han ido enmascarando y superponiendo a lo largo de toda la 'vida' de este importante centro funerario y ceremonial.

Palabras clave: Megalitismo; Valle del Duero; 'vidas megalíticas'; rituales de clausura; reutilización; Campaniforme.

Aвstract: The passage grave of El Terińuelo is located in the village of Aldeavieja de Tormes (province of Salamanca). It is part of one of the most important and well-documented megalithic areas of inner Iberian Peninsula. Since before 1930 several archaeological works have taken place at this passage grave, thanks to which it has been possible to reconstruct parts of its 'biography'. The last excavation season, conducted by the authors of this paper in 2005, discovered new evidences of the use sequence and, mainly, of the closure event of this monument. In this paper the archaeological remains of this single ritual ceremony will be presented within the context of the different use phases of the dolmen, with a biographic approach which attempts to deal with the complex superposition of ritual practices of the 'life-history' of this important ceremonial and burial centre.

Key words: Megalithism; Douro Valley; 'Megalithic life-histories'; closing rituals; reuse; Bell Beaker. 


\section{El Terińuelo en su paisaje megalítico: localización y emplazamiento ${ }^{1}$}

El dolmen de El Terińuelo se sitúa unos 800 $\mathrm{m}$ al sE de la localidad salmantina de Aldeavieja de Tormes $-250 \mathrm{~m}$ a la izquierda del conocido como "Camino de la Aceña" (Fig. 1)-, a 905 msnm y $49 \mathrm{~m}$ por encima del antiguo cauce del río (Fig. 2). Está ubicado en una destacada elevación de la margen izquierda del Tormes, próxima al embalse de Santa Teresa, desde donde la vista alcanza sin dificultad la antigua vega del río, hoy ocupada por el embalse y todo un amplio paisaje de decenas de kilómetros (Fig. 3).

La subordinación de los emplazamientos megalíticos a la red hidrográfica es una de las características recurrentes del Megalitismo salmantino (López Plaza, 1982: 1). En general, suelen hallarse en los bordes de las primeras terrazas fluviales (Santonja, 1987: 200) o en los cursos inferiores de los ríos o pequeños arroyos, bien cerca de su confluencia con otros o de su desembocadura en el río principal. Normalmente, se ubican en espacios abiertos, alejados de lugares muy elevados, y con una buena visibilidad, pero donde también puedan ser vistos con facilidad. Ésta es una de las razones por las que, en muchas ocasiones, se encuentran en puntos visibles junto a los ríos, sin duda una las vías de comunicación y tránsito más importantes durante la Prehistoria. De este modo, los megalitos habrían funcionado como referentes espaciales claves en los desplazamientos humanos -indicando zonas de pastos, vados naturales,

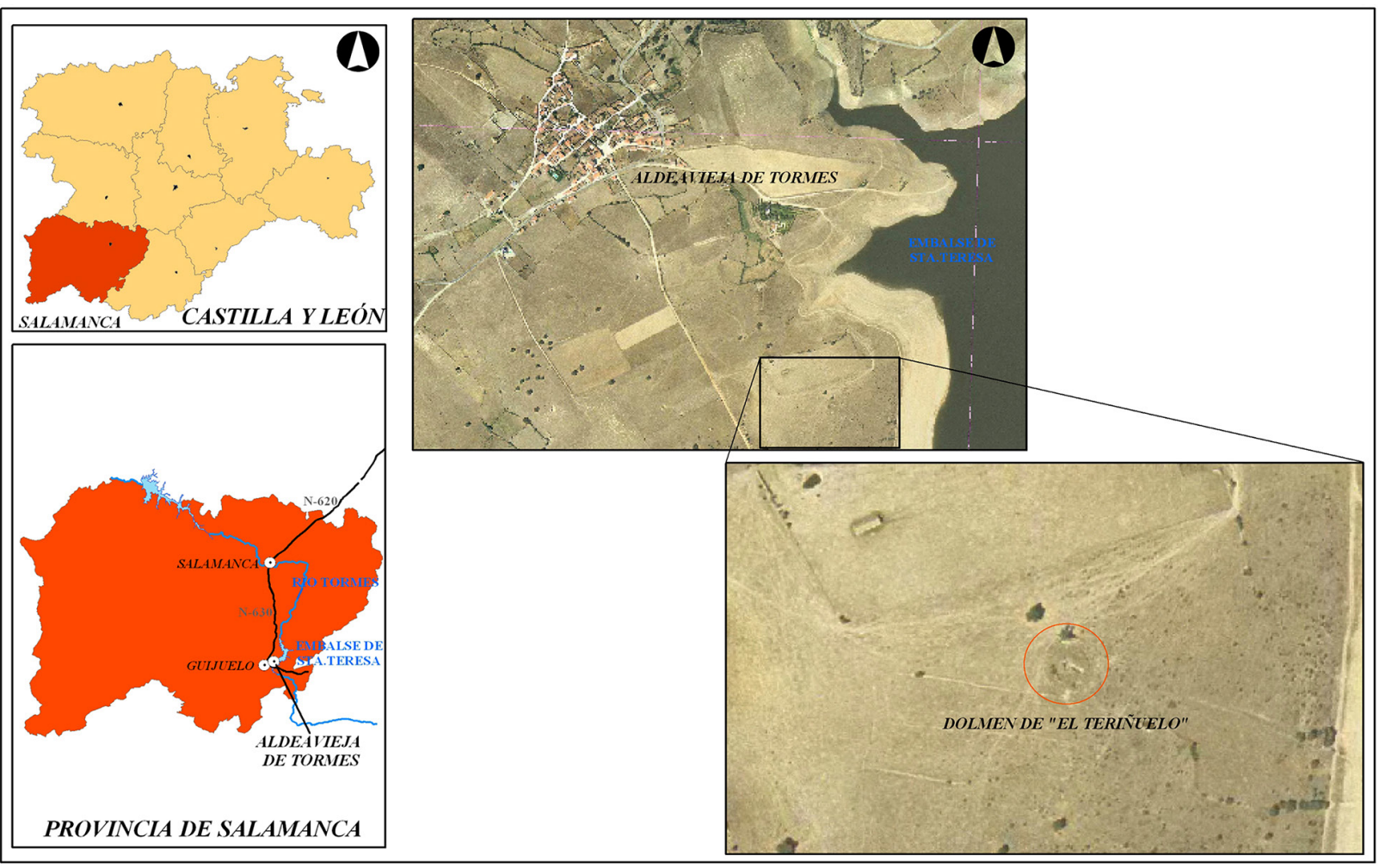

FIG. 1. Localización de El Teriñuelo (Aldeavieja de Tormes, Salamanca).

1 La campaña de excavación llevada a cabo en 2005 en este yacimiento y los trabajos de investigación derivados de la misma han sido promovidos y financiados por la Junta de Castilla y León. fuentes de agua, etc.- $y$, a su vez, al situarse en puntos estratégicos del paisaje, habrían servido a modo de hitos y marcadores territoriales para todo el que frecuentase su entorno. Todos estos rasgos permiten 


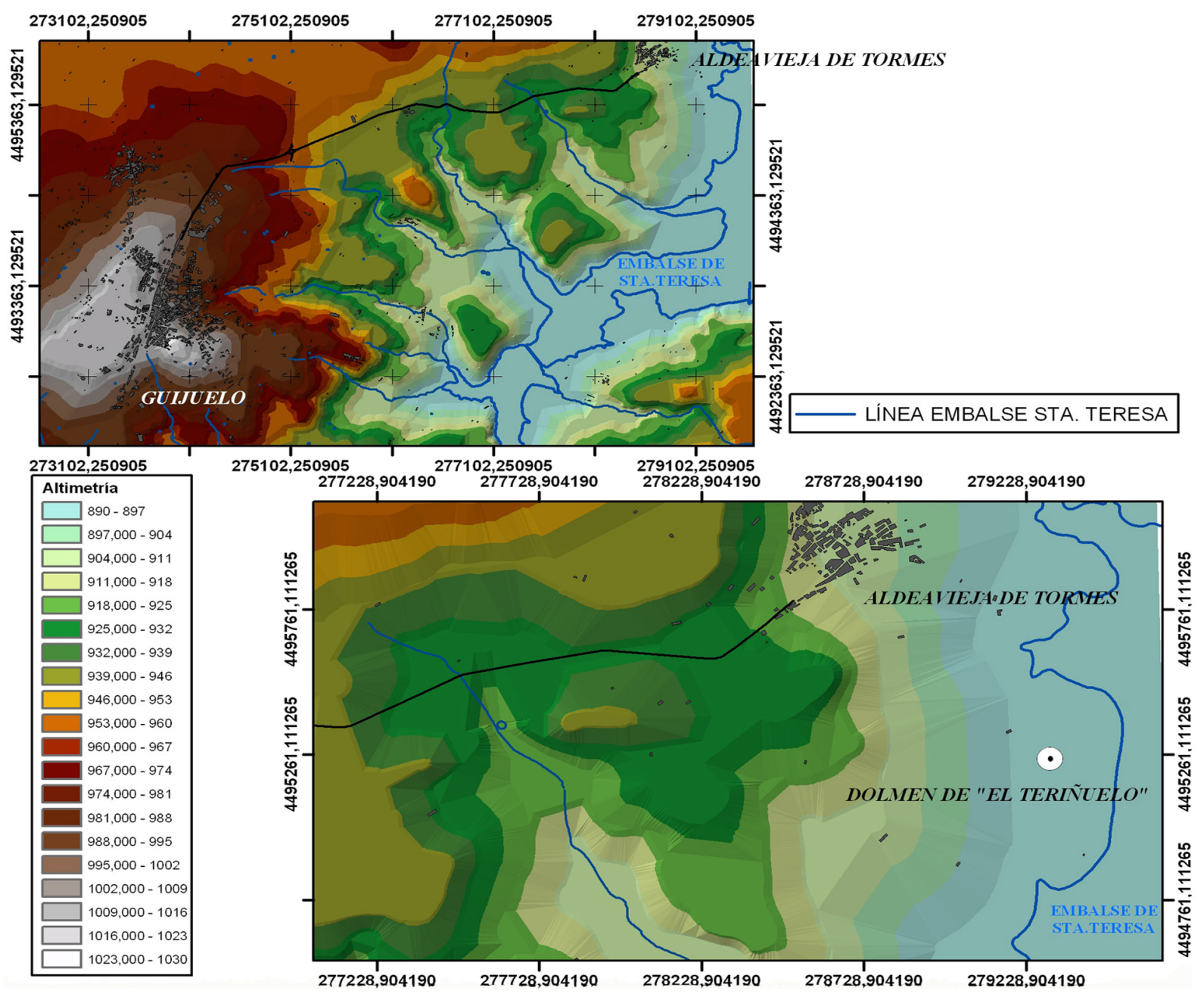

Fig. 2. Mapa topográfico del área de ubicación de El Teriñuelo.

definir a los monumentos megalíticos con este emplazamiento como "dólmenes de fondo de valle” (Delibes y Santonja, 1986: 136; Delibes et al., 1997: 800).

El dolmen de El Terińuelo pertenece al denominado núcleo dolménico de Aldeavieja-Salvatierrra (Delibes et al., 1997: 788), uno de los conjuntos megalíticos documentados a lo largo del Tormes. Este grupo está formado, al menos en la actualidad, por otros tres monumentos -Prado de la Nava, Prado Nuevo y otro Terińuelo- localizados en Salvatierra de Tormes y en la margen derecha del río. El diferente emplazamiento de El Teriñuelo de Aldeavieja le dota de ciertos rasgos particulares que lo diferencian, sutilmente, del resto (Figs. 1 y 2). Por un lado, mientras todos los demás se sitúan cerca de la confluencia del regato Saldaña con el Tormes, este monumento se aparta ligeramente, ubicándose sobre un destacado promontorio en la otra margen del río. Su situación elevada también lo distingue puesto que, si bien todos los megalitos que conforman este grupo cuentan con un amplio dominio visual del valle y con una clara intervisibilidad entre ellos, el campo visual de este dolmen es significativamente mayor, superando con mucho el propio valle y alcanzando decenas de kilómetros (Fig. 3). Gracias a esta posición elevada, es el único que no se ha visto afectado por las aguas del embalse, que 
llegan a cubrir a los restantes de manera parcial -Prado Nuevo y Prado de la Nava- (Delibes y Santonja, 1986: 100-104) o completa-El Terińuelo de Salvatierra- (Santonja et al., 1996; Santonja, 1997: 66). Durante un tiempo, se agregó a este grupo otro dolmen ubicado en la Viña de Esteban García, catalogado como tal por el padre Morán puesto que en el lugar se hallaron numerosas hachas pulimentadas y fragmentos de barro cocido (Delibes y Santonja, 1986: 106 y 108). Sin embargo, tras un fuerte periodo de estiaje que dejó al descubierto el yacimiento en 1992, se comprobó que, en realidad, se trataba de un lugar de hábitat (Delibes et al., 1997: 792-796) ${ }^{2}$.

\section{Historia de la investigación de El Teriñuelo}

\subsection{Los trabajos previos}

El agustino César Morán fue quien primero intervino en este yacimiento, a finales de los años 20, concretamente en la cámara y en parte del corredor y del sector oriental del túmulo (Morán, 1931: 52-60). Posteriormente, Maluquer de Motes (1956) realizó una primera sistematización de la información recogida por Morán y una actualización del inventario megalítico salmantino. Nuevos trabajos de catalogación y revisión se llevaron a cabo a mediados de la década de los 80 por parte de G. Delibes y M. Santonja (1986: 26-33, figs. 5-10). En esta obra se recapitulan los hallazgos de Morán y se ofrece una nueva planta de la arquitectura de El Teriñuelo que,

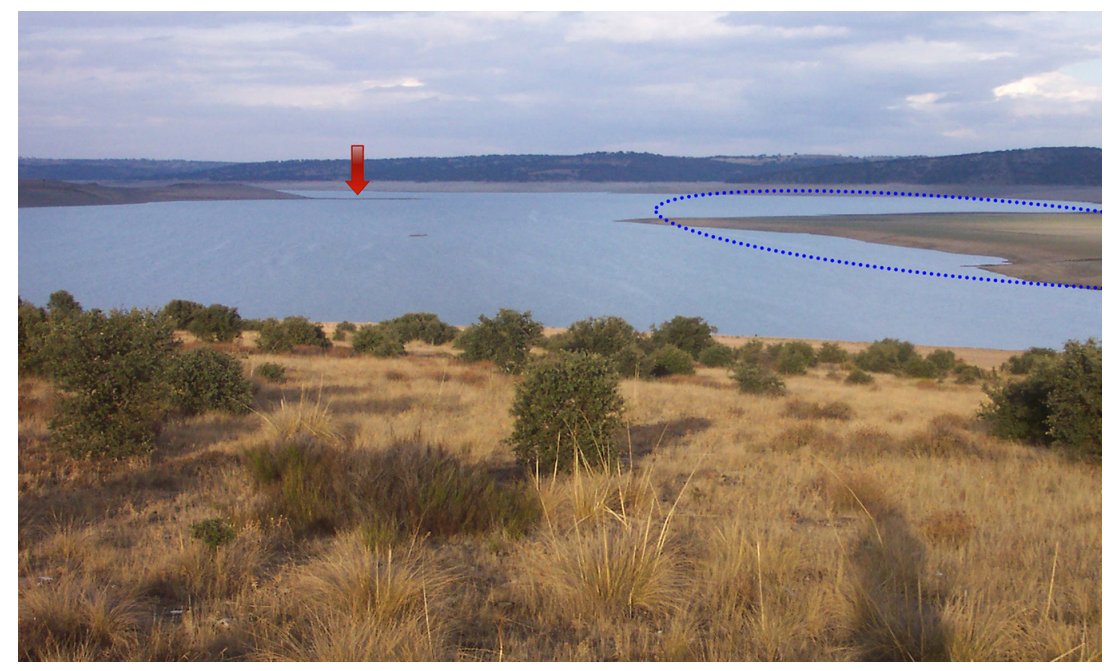

a su vez, actualiza la publicada anteriormente por $\mathrm{S}$. López Plaza (1982: 14 y fig. 24). En este momento, aún no estaba claro el trazado del corredor y, de hecho, los autores aluden a la posibilidad, ya sugerida por Morán, de que su arranque estuviese ubicado en el sector meridional de la cámara.

En 1985-1986 se decidió realizar una intervención arqueológica en el yacimiento, llevándose a cabo una limpieza sistemática de la cámara, el cribado de las tierras procedentes de las excavaciones de Morán, labores de planimetría y las primeras excavaciones en el corredor que desvelaron por fin su localización hacia el SE. Además, se procedió a recolocar algunos ortostatos que habían sido derribados o desplazados a lo largo de las últimas décadas. Estos trabajos fueron dirigidos por M. Santonja, N. Benet y A. García Frías. Nuevas intervenciones tuvieron lugar bajo la dirección de J. Soler Díaz, en 1989, y de M. ${ }^{a}$ R. Pérez Martín, en 1989 y 1990, las cuales se centraron fundamentalmente en el corredor. Todas estas campañas arqueológicas se enmarcaron dentro de un proyecto de recuperación, limpieza y reexcavación de los dólmenes de la cuenca media del Tormes.
2 Cf. también el Informe Técnico elaborado por STRAто (Gabinete de Estudios sobre Patrimonio Histórico y Arqueológico) en 1992: Excavación arqueológica de urgencia en el yacimiento "Viña de Esteban García", Salvatierra de Tormes, Salamanca, depositado en el Servicio Territorial de Cultura de Salamanca (JcyL), Unidad Técnica de Arqueología.

FIG. 3. Vista panorámica del embalse de Santa Teresa desde El Terinuelo, con indicación del yacimiento de la Viña de Esteban Garcia (flecha) y la ubicación aproximada de los dólmenes del Prado de la Nava, Prado Nuevo y El Teriñuelo de Salvatierra (linea punteada). 

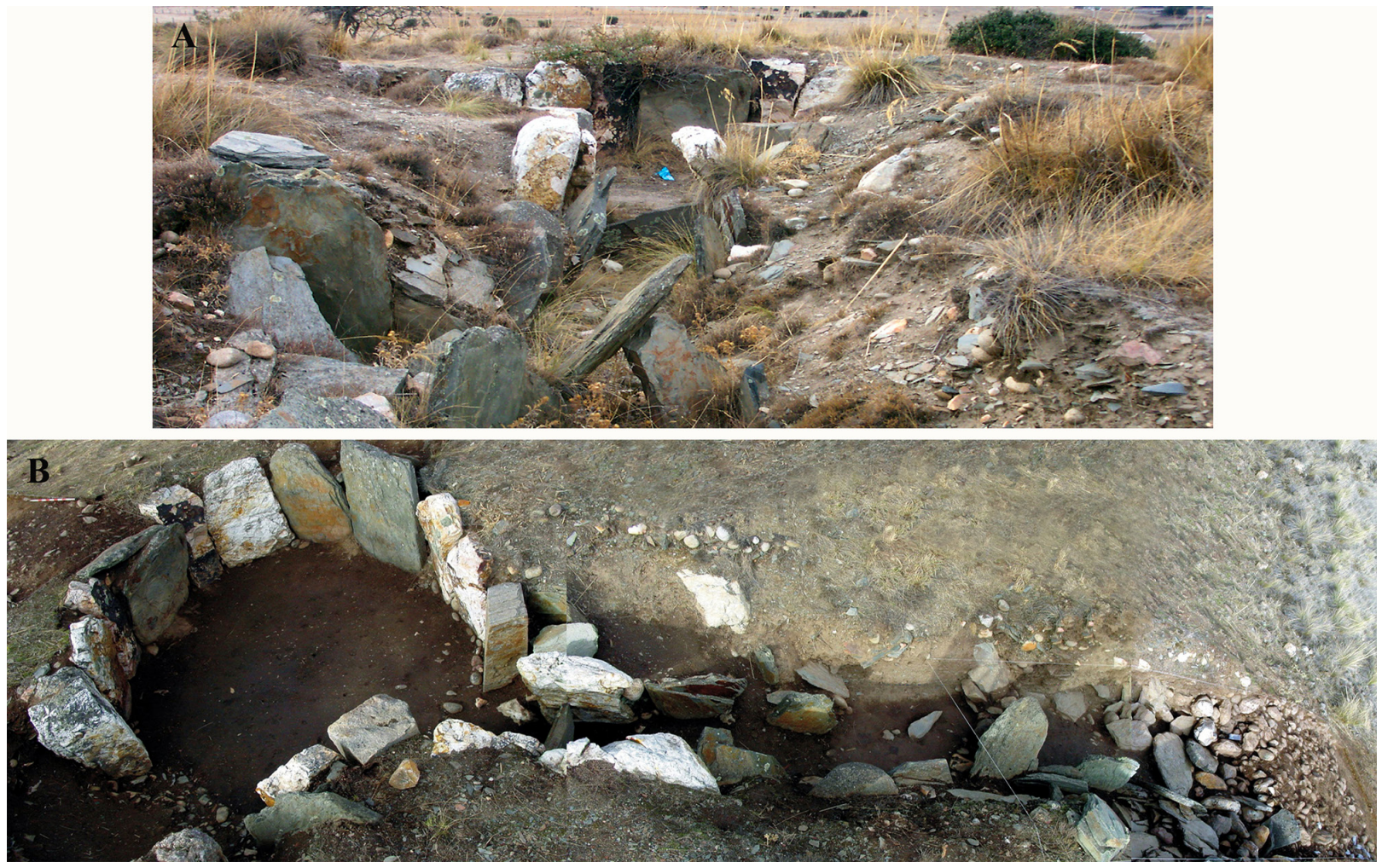

Fig. 4. Imagen general de El Teriñuelo: A) antes y B) después de la campaña de 2005.

\subsection{La campaña de 2005}

En noviembre de ese año tuvo lugar la última intervención arqueológica llevada a cabo en este dolmen, bajo la dirección científica de los firmantes de este artículo y dentro del proyecto de $A c$ tuación Integral en el Megalitismo de la provincia de Salamanca, promovido por la JCyL y ejecutado por Aratikos-Arqueólogos SL ${ }^{3}$. Los objetivos principales fueron la limpieza de las secciones resultantes de los trabajos anteriores, tanto en la cámara como en el arranque del pasillo, y la excavación del tramo final del corredor y de algunos sectores de la estructura tumular. Los resultados obtenidos permitieron

3 Cf. los Informes Técnicos elaborados en 2005 por Aratikos-Arqueólogos, sL: Actuación arqueológica en el dolmen de El Teriñuelo, Aldeavieja de Tormes (Salamanca). Análisis de la documentación previa y Trabajos de excavación arqueológica en el dolmen de El Teriñuelo en Aldeavieja de Tormes (Salamanca), ambos depositados en el Servicio Territorial de Cultura de Salamanca (JcyL). ahondar en algunas cuestiones relativas a la estructura arquitectónica -sistema constructivo del túmulo, posibles estrategias de cubierta de la cámara, etc. (Figs. 5 y 7) - y en la compleja secuencia de utilización del dolmen, constatándose, además, la urgente necesidad de restaurarlo y ponerlo en valor dado el lamentable estado de abandono en que se encontraba (Fig. 4A). Pero, sin lugar a dudas, el hallazgo más interesante fue el del evento de clausura ritual llevado a cabo en la zona de acceso al monumento (Figs. 9-10).

\section{Las características arquitectónicas del monumento}

El dolmen de El Terińuelo se ajusta perfectamente al modelo canónico de sepulcro de corredor (Figs. 4B y 5A), el más representativo dentro del catálogo megalítico de la provincia salmantina y, en general, de todo el interior peninsular. Pertenece al 
grupo de dólmenes de grandes dimensiones, con cámaras casi circulares formadas por un número elevado de ortostatos y pasillos claramente diferenciados, junto a otros monumentos salmantinos como El Terińuelo de Salvatierra, el Prado de la Nava, La Navalito o El Torrejón, entre otros (López Plaza, 1982: 2 y 14).

La cámara, de forma ovalada, conserva trece ortostatos in situ (Fig. 5A). La ausencia de dos de ellos en su lado meridional ya fue constatada por Morán, quien decidió seguir excavando en esa zona ante la posibilidad de que dicho vacío se debiese a la existencia de una cámara secundaria (Morán, 1931: 52-53). Los ortostatos, de diverso tamaño, dibujan una planta de 4,5 m de diámetro máximo y 3,5 m de mínimo, con una altura que podría oscilar entre 1,5-1,6 m. Estos grandes bloques irían encajados en sendas fosas de cimentación y, posteriormente, calzados mediante acumulaciones de cantos rodados (Fig. 6в). Se han registrado algunas evidencias
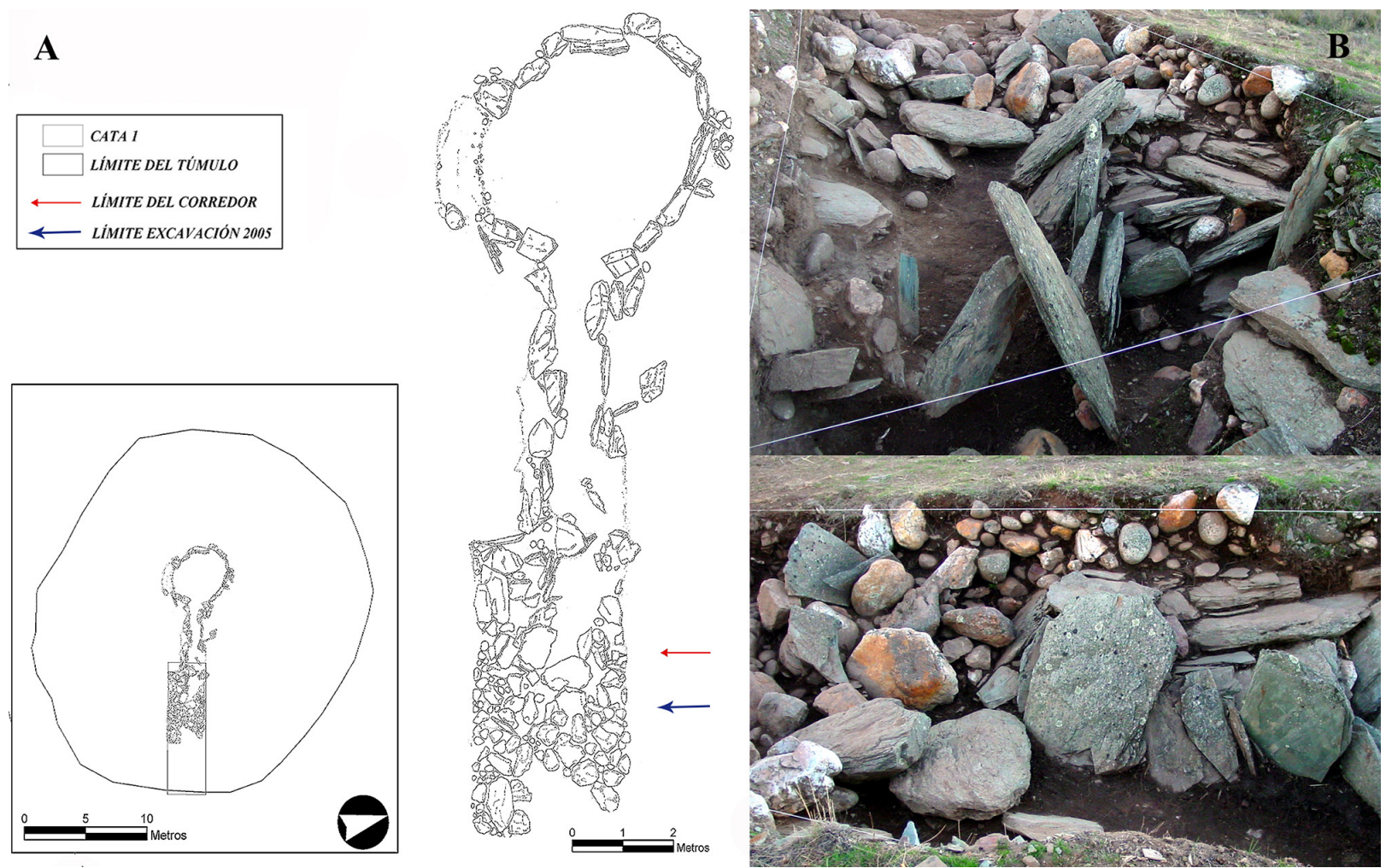

acerca del posible sistema de cubierta de la cámara. Por un lado, los ortostatos aparecen ligeramente inclinados hacia el interior, de modo que podrían haber funcionado como pilares de alguna suerte de estructura central. Además, se ha documentado una laja de pizarra dispuesta sobre la parte superior de uno de estos bloques, el cual se ha ido inclinando notablemente hacia el interior por esta razón (Fig. 6A). Por otro lado, durante la excavación de 1986 se halló una gran laja de cuarcita blanca en la zona de contacto entre el corredor y la cámara, que fue interpretada como la piedra que haría las veces de dintel en el acceso al recinto cameral. Por último, se han recogido testimonios orales que aseguran que, antiguamente, una gran lastra de pizarra cubría la parte superior de la esquina norte. Por tanto, la hipótesis de la existencia de una cubierta pétrea adintelada, elaborada con varias lajas de pizarra superpuestas, se antoja bastante acertada (Santonja, 1997: 71), teniendo en cuenta, además, que este

Fig. 5. Dolmen de El Teriñuelo: A) plano general de la arquitectura y de la estructura de clausura documentada en 2005; B) imágenes de la composición interna del túmulo en el lienzo sur del pasillo. 
sistema de cubierta ha sido propuesto para las cámaras de otros dólmenes salmantinos, como el de La Casa del Moro en Gejuelo del Barro (Delibes y Santonja, 1986: 78 y 156-157). Pese a todas estas evidencias, no se puede descartar por completo la posible presencia de una cubierta vegetal (Delibes y Santonja, 1986: 156), al menos en ciertos sectores, dado que uno de los ortostatos de acceso a la cámara presenta rebajes que podrían estar relacionados con el soporte de algún elemento de cobertura de esta naturaleza (Fig. 6в).

Se han documentado una serie de bloques que podrían formar parte de una suerte de anillo peristalítico, ya intuido desde intervenciones anteriores (Delibes et al., 1997: 790), que estaría relacionado con funciones de contención y soporte del peso de los ortostatos de la cámara y de su posible cubierta (Figs. 5A y 6A). Anillos de este tipo se han podido identificar, de forma mucho más clara, en otros dólmenes de la provincia, como en La Casa del Moro en Casillas de las Flores (López Plaza et al., 2000: 274) o en el de Linejo en Matilla de los Caños del Río (Delibes y Santonja, 1986: 88 y 145-146), y de otras regiones meseteñas próximas, como en el monumento burgalés de Cubillejo (Delibes y Rojo, 1988: 8-13 y fig. 2) o en los toledanos de Azután y La Estrella (Bueno, 1991: 20 y figs. 28, 58 y 87, respectivamente). Cabe destacar el monumento salmantino de La Ermita, en Galisancho, donde se han registrado tres anillos pericamerales concéntricos, conformados por grandes bloques pétreos dispuestos horizontalmente, de los que el más cercano a la cámara funcionaría a modo de peristalito, mientras que los otros servirían como elementos de contención del propio túmulo (Delibes y Santonja, 1986: $72-73$ y fig. 31; 1987: 181 y fig. 1; Santonja, 1997: 72 y fig. 17).

El corredor, orientado hacia el SE, muestra un trazado bastante regular y también conserva, prácticamente, todos sus ortostatos in situ -más de una decena-, que, al igual que en la cámara, se hallan reforzados en su base por cantos de gran tamaño a modo de calzos o contrafuertes. Su alzado es bastante inferior al del recinto cameral y su anchura va disminuyendo progresivamente desde la zona de contacto

(C) Universidad de Salamanca con la cámara hacia el acceso al monumento. $\mathrm{Su}$ longitud aproximada es de $7 \mathrm{~m}$, sin alcanzar el límite exterior del túmulo, rasgo que, pese a que ya se intuía previamente (Delibes et al., 1997: 790), no se ha podido corroborar hasta la excavación de 2005 (Fig. 5A). El lienzo septentrional se encuentra bastante deteriorado (Fig. 5B), fundamentalmente en su tramo más alejado de la cámara, deterioro que ya se documentó en el momento de su descubrimiento (Benet et al., 1997: 453). En relación al sistema de cubierta, además de la presencia ya mencionada de un bloque que haría las veces de dintel, se han documentado varias planchas de pizarra, de mediano y gran tamaño, desplazadas de su ubicación original, que podrían haber servido a modo de 'lajas de cubierta'. Este tipo de cobertura del corredor se ha registrado en otros monumentos de la región como en La Casa del Moro, en Gejuelo del Barro (Morán, 1931: 13-15; Delibes y Santonja, 1986: 78 y 161), y en Lumbo de Valdesancho, en Lumbrales (Morán, 1931: 20; Delibes y Santonja, 1986: 81 y 161), además de en otras zonas peninsulares, como en el dolmen burgalés de Las Arnillas (Delibes et al., 1986: 12-14, fig. 2). Hay que señalar que, durante la campaña de 1989, en el sector de la entrada al corredor -Cuadro E8- se halló un pequeño hoyo de forma alargada y sólo $6 \mathrm{~cm}$ de profundidad que, quizás, podría haber servido de cimentación de algún elemento arquitectónico de escasa entidad ubicado en el acceso al monumento.

El túmulo es de planta oval y mantiene un buen estado de conservación. Actualmente presenta 25 $\mathrm{m}$ de diámetro (Fig. 7), aunque es posible que en origen alcanzase los $32 \mathrm{~m}$ y una altura superior a los 2,5 m (Delibes y Santonja, 1986: 26). En 2005 se realizaron dos catas de $2 \mathrm{~m}$ de anchura desde la cámara hasta el límite tumular exterior con el fin de descubrir la coraza pétrea en todo el alzado del túmulo (Fig. 7). Además, las labores de limpieza y perfilado de las zonas intervenidas previamente, así como la excavación en la zona de acceso, dejaron al descubierto varios cortes de la estructura tumular, pudiéndose documentar su composición interna en distintas partes del monumento -cámara, pasillo y zona de entrada- (Fig. 5в). Todo ello 

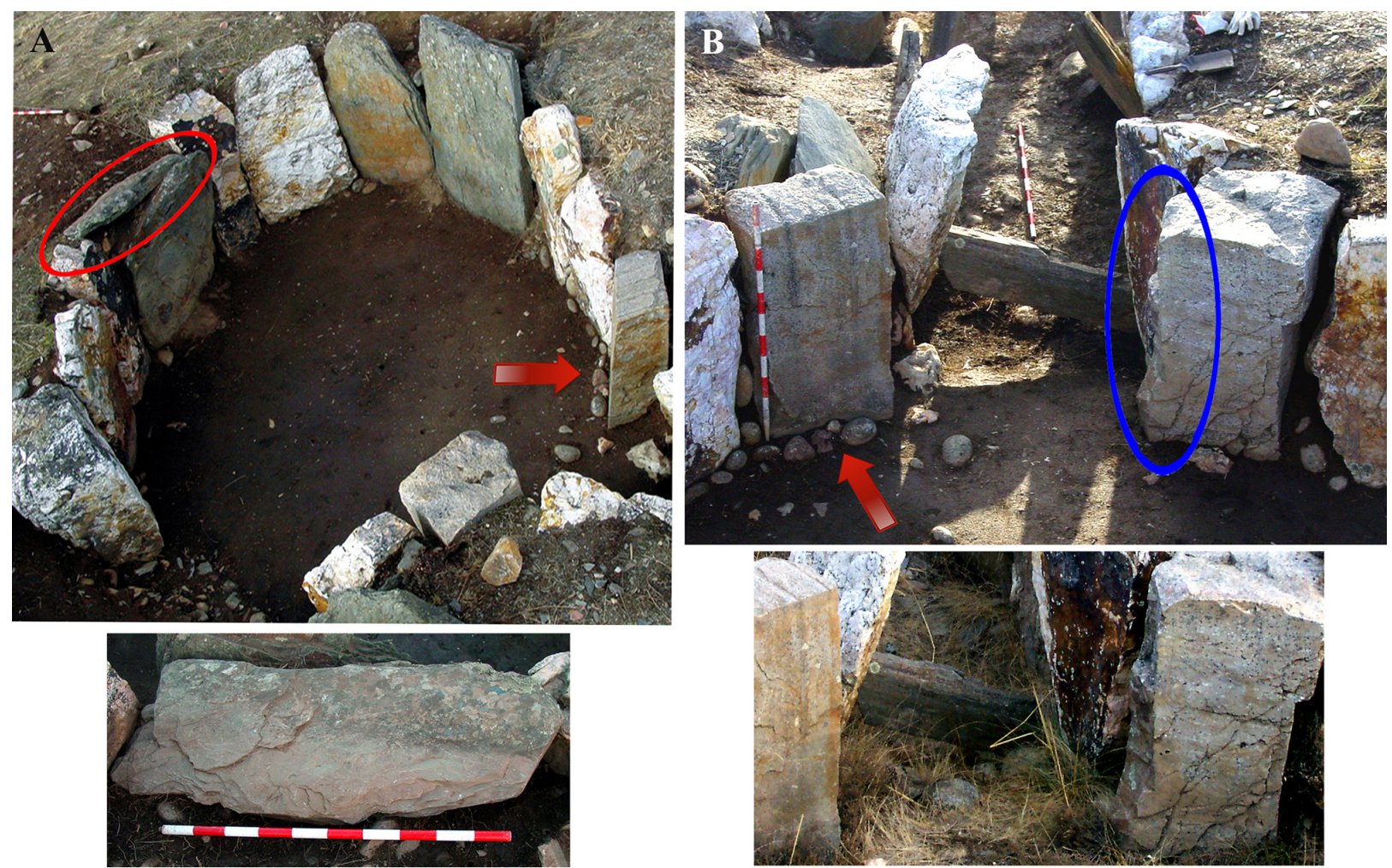

Fig. 6. Distintas perspectivas de la cámara megalitica: A) posible laja de cubierta’; B) rebajes en ortostatos para facilitar la sustentación de la cubierta; el sistema de estabilización mediante la acumulación de cantos en la base de los ortostatos, ambos marcados con flechas.

permitió confirmar que la estructura, tanto interna como externa, de este túmulo sigue un esquema bastante complejo, más allá de la mera acumulación caótica de bloques pétreos. Su núcleo central está formado por grandes lajas de pizarra dispuestas horizontalmente y superpuestas -en ocasiones contrapeadas- unas sobre otras, mientras que los espacios entre ellas aparecen rellenos con tierra y cantos de cuarzo y cuarcita de diferentes tamańos (Fig. 5B). Esta fórmula arquitectónica da lugar a un entramado interno a modo de forjado o urdimbre que proporciona una gran estabilidad y resistencia al túmulo, evitando su erosión por el paso del tiempo. Sobre esta acumulación de pizarras, se extiende una coraza pétrea a base de bolos de cuarzo y cuarcita (Figs. 5в у 7). Esta disposición ordenada de los componentes de la masa tumular estaría orientada, sin duda alguna, a mejorar sus cualidades prácticas y su funcionalidad como elemento arquitectónico fundamental de toda la construcción (Delibes y Santonja, 1986: 145).

En las capas más superficiales de la estructura tumular se han registrado ciertos efectos estéticos, resultantes de la combinación de piedras de distinta naturaleza y color. Todo el perímetro en torno a la cámara presenta una concentración significativa de pequeñas lajas de pizarra, que pudo haberse dispuesto de manera intencional, con el fin, quizás, de señalar de forma gráfica el contorno de la misma (Fig. 7). La distribución de los bloques pétreos de la coraza tumular tampoco es aleatoria, sino que responde a ciertos criterios de organización que se manifiestan, de forma clara, en la existencia de, al menos, un posible anillo pericameral formado por cantos de cuarcita de pequeńo y mediano tamaño mezclados con lajas de pizarra de similares dimensiones (Fig. 7). Este anillo, a diferencia del peristalito, no tendría un propósito funcional como 
elemento sustentante sino que, más bien, se trataría de un recurso arquitectónico efectista y visual. Este empleo de materiales con una finalidad aparentemente estética también se ha documentado en la cámara, conformada por ortostatos de pizarra, cuarcita blanca y cuarzo alternados, mientras que el corredor está realizado a base de bloques de cuarzo y cuarcita blanca, en la zona inmediata a la cámara, y de pizarra, en el resto (Figs. 5в у 6). De este modo, la monumentalidad propia de este dolmen, ya de por sí realzada por su ubicación sobre un promontorio natural, se acentuaría con el uso de otras estrategias constructivas como los juegos de color o el 'añadido' de ciertos elementos ornamentales -como los círculos concéntricos pétreos, a modo de anillos pericamerales, o el lajeado superficial de pizarra dispuesto en torno a la cámara-. Este tipo de efectos estéticos están presentes en algunos megalitos cercanos, como en El Terińuelo de Salvatierra, cuyo corredor está elaborado con cuarzo y pizarra
(Santonja et al., 1996: 19), o en las cámaras de Linejo, La Ermita (Delibes y Santonja, 1986: 88 y $72-$ 73, respectivamente) o El Torrejón (López Plaza et al., 2008: 116-122). Fuera de la provincia salmantina también se han registrado casos excepcionales, como el del tholos soriano de La Sima (Rojo et al., 2013: 215-217, fig. 2) o el de la mamoa de Castelo I, en Vila Real (Sanches et al., 2005: 19-21). Más habitual es el hallazgo de combinaciones de tierra y/o piedras de distinto color, tamaño o textura en diferentes capas o niveles de los túmulos megalíticos, como ocurre en el vecino dolmen de Prado de la Nava, que presenta un lajeado de pizarra superficial sobre la coraza tumular (Delibes y Santonja, 1986: 103 y 145). Esta práctica también se ha constatado, entre otros, en el túmulo de La Sima, compuesto por bloques de caliza que fueron cubiertos, en un sector concreto del mismo, por un lajeado de areniscas (Rojo et al., 2013: 213-215, fig. 4), o en el coruñés de Forno dos Mouros 5, en el que

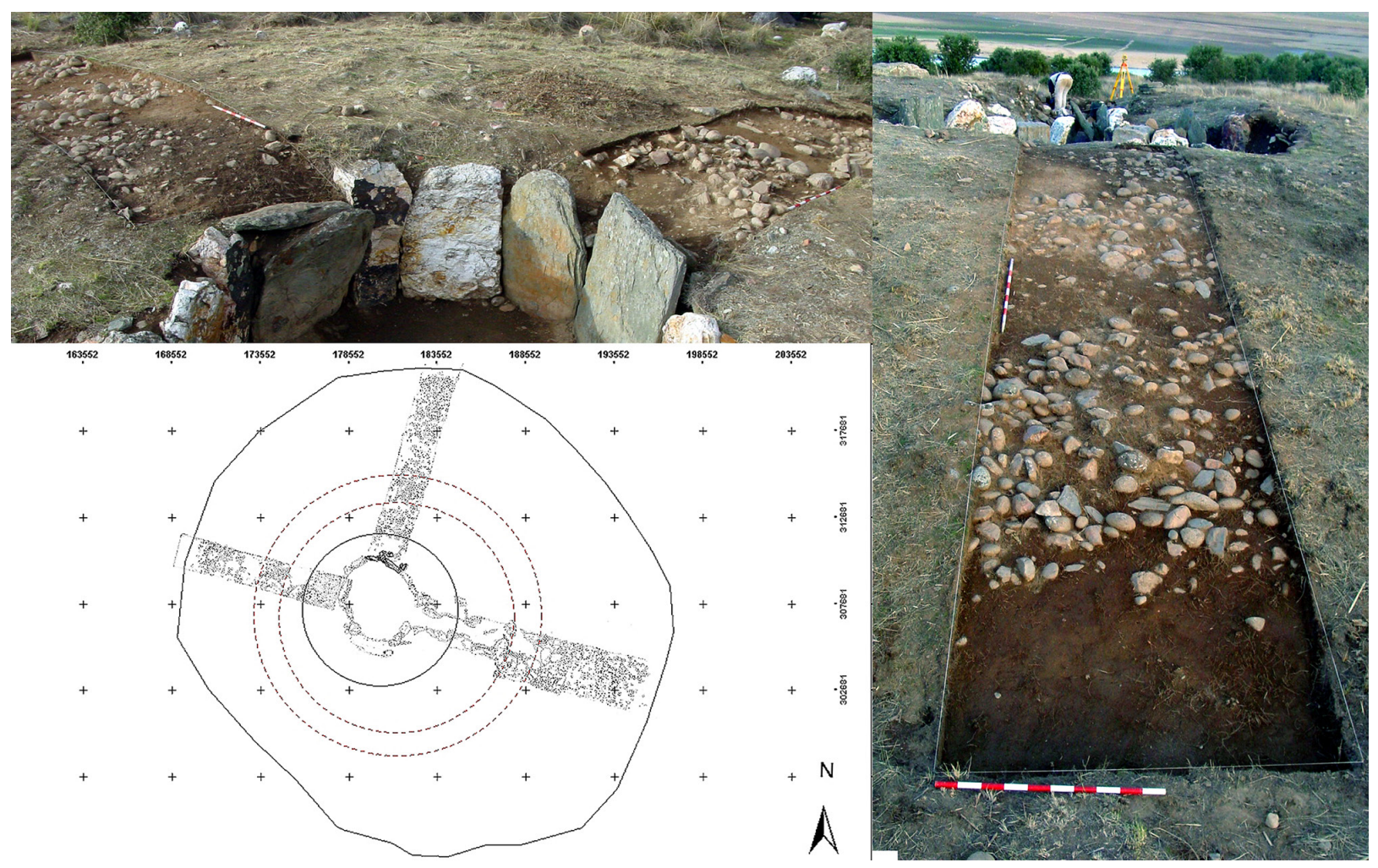

Fig. 7. Plano general del dolmen en 2005 e imágenes de las catas realizadas; pueden observarse los restos superficiales del anillo de pizarras pericameral (círculo continuo) y del posible círculo perimetral (lineas discontinuas). 
la masa tumular correspondiente a su segunda fase constructiva y de remodelación se conforma por la mezcla de, al menos, dos tipos de tierra de coloración y textura diferente (Mañana, 2005: 55-60).

\section{La 'biografía' del monumento: uso, clausura y reutilización}

El término 'biografía' o 'life-history' aplicado a los monumentos megalíticos ha sido teorizado y discutido, principalmente, en la bibliografía anglosajona (Bradley, 1993; Bradley y Williams, 1998; Hingley, 1996; Rogers, 2013; etc.), generando interesantes debates acerca de la temporalidad de los megalitos y su construcción en 'múltiples fases. Bradley (1993) acunó el concepto de 'after-life' para designar el tiempo posterior al uso o función primaria para el que fueron construidos los megalitos. Sin embargo, otros autores, como Holtorf, no son partidarios de este término ya que implica asumir que, en algún momento, el megalito fue abandonado o entró en desuso. Su propuesta es que el devenir de los megalitos puede ser analizado como si de una 'biografía' se tratase, ya que, al igual que otras manifestaciones arqueológicas, tienen 'life-histories' (Holtorf, 20002008), de modo que han experimentado una etapa de 'infancia' -construcción y uso original-, otra de 'juventud' -primeras reutilizaciones y clausuras-, una 'edad adulta' -reocupaciones por usuarios no constructores de megalitos, cambios de funcionalidad y apropiación político-religiosa de su potencial simbólico-y, por último, una 'vida anciana' -objeto de interés para anticuarios e investigadores, fuente de mitos y leyendas, inspiración para artistas o recurso patrimonial- (Tejedor, 2014: 71-72). Este enfoque biográfico va ligado a una determinada forma de concebir el megalito, no como un yacimiento adscrito a un contexto espacio-temporal concreto, sino como un lugar con una larga proyección temporal, un "monumento para la eternidad" (Delibes y Rojo, 2002: 29; Rojo, Kunst et al., 2005). Por tanto, carece de sentido limitar su interpretación a una forma de uso específica de un periodo cronológico concreto. Al aplicar este enfoque metodológico, se puede ir desentrañando la compleja superposición de deposiciones funerarias y/o votivas, remodelaciones, clausuras, etc., que vertebra cada 'biografía megalítica'.

El análisis de las evidencias arqueológicas registradas en El Teriñuelo, desde esta perspectiva biográfica, ha permitido dibujar una compleja secuencia de uso del monumento. Hay que tener en cuenta que los indicios documentados son sólo los de aquellos eventos que han dejado algún tipo de huella arqueológica perdurable, por lo que es razonable plantear que su historia como foco de actividad ceremonial fue aún mucho más rica y diversa. Los límites cronológicos de cada fase de uso se han establecido a través del análisis cronotipológico de la cultura material asociada, ante la ausencia de fechas radiocarbónicas. En este sentido, resulta sorprendente que, siendo uno de los focos megalíticos más nutridos y conocidos del centro-norte peninsular, el Megalitismo salmantino apenas cuente con dataciones -sólo están disponibles una fecha de C14 procedente de El Guijo de las Navas I (Villalobos, 2014: 7) y dos escuetas referencias a dataciones mediante TL sobre muestras de los túmulos de La Ermita y La Torrecilla de Terradillos (Delibes, 2010: 25 y 43)-. Por otra parte, la ausencia de una estratigrafía vertical en este dolmen, circunstancia bastante generalizada en el fenómeno megalítico, ha llevado a que el análisis cronotipológico de la cultura material se haya basado, fundamentalmente, en su comparación con paralelos arqueológicos procedentes de contextos semejantes, en los que sí que se ha podido establecer un comportamiento diacrónico de los objetos depositados en los megalitos (Jorge, 1987: 120-123; Kalb, 1987: 104-109; Delibes y Rojo, 2002: 26-29; Delibes, 2010: 33-36; Rojo, 2014: 62-66).

En las páginas siguientes se plantea un modelo interpretativo para la 'biografía' de El Teriñuelo y se proponen posibles hipótesis sobre la asociación de determinados elementos materiales y prácticas rito-funerarias con cada uno de los episodios de uso definidos. Dadas las limitaciones de extensión del texto, se ha considerado conveniente exponer conjuntamente la descripción de las evidencias arqueológicas y su interpretación, con el fin de ofrecer 
la máxima información posible y facilitar su comprensión al lector. Hay que señalar que el propósito de este artículo no es describir con detalle todas las evidencias registradas en las sucesivas intervenciones arqueológicas que han tenido lugar en el monumento -información que puede ser consultada en las distintas publicaciones y memorias de excavación citadas a lo largo de este artículo-, sino presentar los resultados de la campaña de 2005, aún inéditos, y ofrecer una hipótesis interpretativa de estos hallazgos en el contexto general del propio dolmen.

\subsection{Fases I y II (mediados-finales del IV milenio cal. $B C)$ : construcción y uso fundacional}

Estas fases de ocupación, protagonizadas por los primeros usuarios del monumento, carecen de una cronología precisa al no contar con ninguna datación. Como hipótesis, se podría proponer una fecha aproximada de mediados del IV milenio cal. BC para la erección e inicio de la actividad en este megalito, dentro de la denominada 'fase de implantación' de los sepulcros de corredor en el interior peninsular (Delibes et al., 1997: 797; Delibes, 2010: 30-31). En este sentido, las dataciones disponibles establecen un intervalo entre el 37003200 cal. BC, para el grupo megalítico de la Lora burgalesa (Delibes y Rojo, 2002: 23-24), y entre el 3600-3100 cal. BC, para el de la Serra de Aboboreira (Cruz, 1995: 82-89).

Las evidencias arqueológicas que se vinculan a esta inicial 'etapa biográfica' han sido, por lo general, halladas fuera de contexto. Parte de ellas fueron registradas por Morán (1931: 53-60 y láms. XVI-XVIII), procedentes de la cámara y de la coraza tumular más cercana a la misma, mientras que, en su mayoría, se recuperaron en 1985, al llevar a cabo el cribado de las tierras extraídas por el agustino (Benet y Santonja, 1990: 281-282) ${ }^{4}$. Los materiales depositados a lo largo de estos episodios de uso se corresponden con el tradicional 'kit' megalítico,

4 Cf. además Informe Técnico de Aratikos-ArqueóLOGOS, SL: Actuación arqueológica..., cit. n. 3: 12-13, 37-40 y Anexo 2a. descrito en numerosas ocasiones en la bibliografía (Jorge, 1983-1984: 41-43; Santonja, 1997: 76-80; Delibes, 2010: 32-41; Rojo, 2014: 62-66; etc.): 18 microlitos geométricos, 2 hachas pulimentadas y restos de al menos otras 6, 12 láminas de sílex completas y cerca de 40 fragmentos, 1 núcleo de cristal de roca, 9 prismas de cuarzo y varias decenas de lascas y restos de talla, tanto de sílex como de cuarzo. También podrían formar parte de este grupo más de 3000 cuentas de collar de distinta materia prima y tipología - destacan, por su singularidad, 3 elaboradas en cerámica-, 11 colgantes, 1 placa redondeada de pizarra, 1 rectangular de piedra con posibles decoraciones esquemáticas y restos de pigmento. En este mismo contexto, se recuperaron otros elementos que, por su tipología, estarían asociados a la siguiente 'etapa biográfica' -86 puntas de flecha con retoque plano, entre otros- (Delibes y Santonja, 1986: 202-205; Santonja, 1997: 79; Jorge, 1987: 122; Kalb, 1987: 106; Delibes, 2010: 33 y 36). Durante la última campaña de excavación, en las capas superficiales del túmulo y en el echadizo de las tierras de la cámara resultante de los trabajos de Morán -uE 101- (Aratikos, 2005b: 39-40), se hallaron algunas piezas ${ }^{5}$ que completarían este conjunto material de las Fases I y II, en concreto 2 microlitos, 1 prisma, 1 colgante y 1 cuenta de collar (Fig. 8A).

Las actividades llevadas a cabo a lo largo de estos primeros momentos de uso estarían protagonizadas por las prácticas funerarias. Si bien es cierto que los restos humanos recuperados son escasos y que se hallaron muy fragmentados -ningún hueso largo, sólo falanges, dientes y astillas-, dispersos y en posición secundaria, la hipótesis de la funcionalidad original de los megalitos como 'casas de muertos' viene avalada por las dataciones realizadas sobre hueso humano en distintos contextos megalíticos, incluidos sepulcros de corredor (Delibes y Rojo, 2002: 29-30; Delibes, 2010: 17 y 23; Rojo, 2014: 66; Rojo et al., 2015: 145; Villalobos, 2014: 7; etc.). Se han hallado evidencias de otras prácticas, más allá del ámbito puramente funerario, como por ejemplo de

5 Cf. Informe Técnico de Aratikos-Arqueólogos, SL: Trabajos de excavación arqueológica..., cit. n. 3: 39-40. 
FASE I

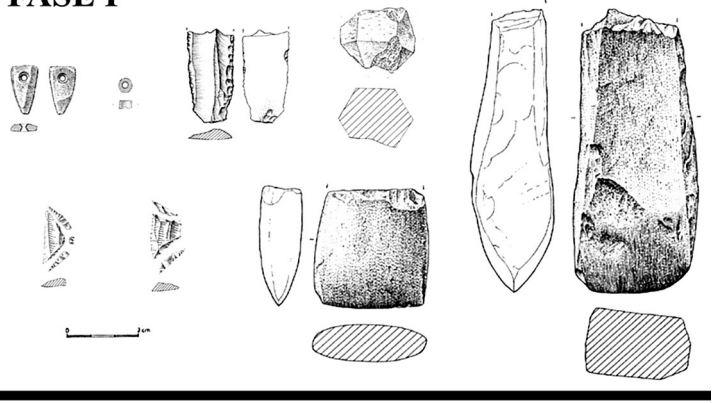

FASE II
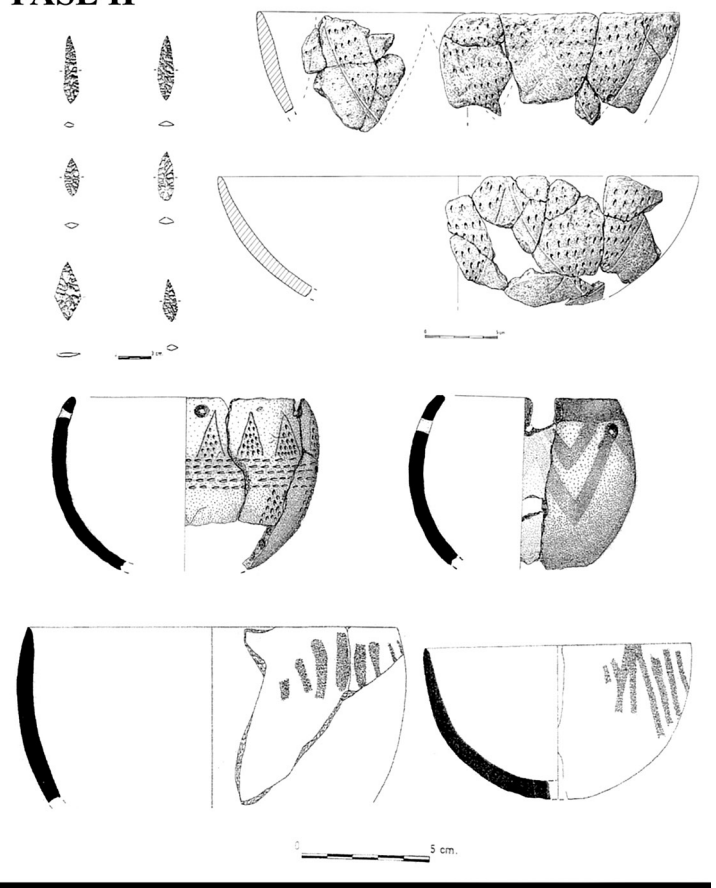

FASE III
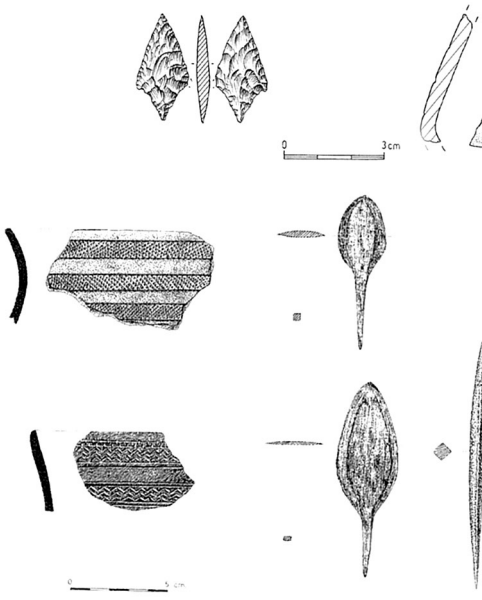

determinadas estrategias de mantenimiento que habrían afectado a la disposición tanto de los restos óseos como de los objetos que los acompañaban (Tejedor, 2014: 79-81). En este sentido, se ha documentado el reordenamiento de algunos elementos de ajuar, como es el caso de un hacha pulimentada que fue depositada de manera intencional en el nivel inferior de la zona de contacto entre la cámara y el corredor, justo en el acceso al recinto cameral. También, en algunos sectores del monumento, sobre todo en la cámara, se han encontrado restos de ocre espolvoreado y varios fragmentos de este pigmento que, aunque parecen no tener suficiente entidad como para conformar un nivel diferenciador dentro del osario, podrían ser el resultado de una práctica de 'finalización de ciclo' (Leclerc y Masset, 1980 y 1987; Narvarte, 2005: 301-303 y 307-311), que se habría llevado a cabo una vez que el uso funerario del espacio sepulcral se diera por concluido. Por otro lado, en varios informes de excavación se hace referencia a la presencia de restos de combustión -carbones, cenizas y manchones de tierra rubefactada- tanto en el interior de la cámara (Morán, 1931: 58) como en el corredor. Estas evidencias parecen encajar más con la práctica recurrente de pequeños fuegos localizados que con un evento concreto de incendio generalizado. Por último, la ausencia de los dos ortostatos de la cámara (Figs. 5A y 6A) podría ser el resultado de un desmantelamiento parcial de época prehistórica, dado que, por sus características -extracción selectiva y ordenada de determinadas lajas-, se asemeja más al tipo de prácticas desarrolladas en este momento que a un episodio intrusivo de cronología reciente. Hay autores que defienden la posibilidad de que el derribo o demolición de algunos elementos arquitectónicos fueron actos deliberados, intencionales y que formaron parte de ciertos

Fig. 8. Selección de materiales recuperados en El Teriñuelo: Fase I-campaña 2005; Fase II-2005: 2 cuencos decorados (sup. dcha.), 1989-1990: cuenco pintado (centro dcha.), 19851986: resto de materiales; Fase III-2005: cerámica y punta de flecha (parte sup.). Dibujos de la campaña 2005: L. Pascual Repiso; resto de imágenes: Benet et al., 1997: fig. 2; Delibes et al., 1997: fig. 6; Aratikos, op. cit. n. 2, anexo 2. ${ }^{\text {; }}$ resto de materiales: C. Morán. 
rituales de clausura (Guy y Masset, 1991: 287-288; Holtorf, 2000-2008; Delibes, 2004: 218-219), hipótesis que puede aplicarse también a la ausencia y fragmentación de los bloques pétreos de cámaras y corredores (Narvarte, 2005: 317), así como de sus lajas de cubierta, que, en ocasiones, se han encontrado partidas en dos en el interior de los recintos camerales. El propio Morán (1931: 53) ya indicó que las gentes prehistóricas llevarían a cabo estas prácticas con una finalidad de "... salida secundaria para que las almas no fueran sorprendidas por los malos espíritus sin tener por donde escapar”... Este tipo de evidencias se ha documentado en otros sepulcros de corredor, tanto desmontes parciales -por ejemplo, en los dólmenes burgaleses de la Cotorrita o Ciella (Tejedor, 2014: 77-78) - como, más excepcionalmente, desmantelamientos completos y sistemáticos de toda la estructura arquitectónica -como ocurre en el singular monumento soriano de La Mina-(Rojo et al., 2015: 145).

\subsection{Fase III (inicios del III milenio cal. BC): clausura}

Esta segunda 'etapa biográfica' se caracteriza por ser muy breve en el tiempo y, a su vez, por el desarrollo de una intensa actividad de cierre que dio lugar a abundantes evidencias arqueológicas. $\mathrm{Al}$ igual que para las fases anteriores, la cronología se ha determinado por el análisis cronotipológico de la cultura material -sobre todo, de determinados tipos líticos y decoraciones cerámicas- que, en este caso, parece remitir a la primera mitad del III milenio cal. вс.

El corredor se halló sistemáticamente colmatado por un potente nivel de tierra compacta y bloques pétreos. Este depósito, excavado durante los años 1986 y 1989 -niveles III y IV, cuadros E6 y E7-6 , presentaba una disposición estructurada: bolsadas de pequeñas lajas de pizarra en los niveles inferiores, cubiertas, posteriormente, por un lecho de tierra compacta y cantos pétreos de cuarzo y cuarcita. Es posible que, justo antes de la clausura, se llevara

6 Cf. Informe Técnico de Aratikos-Arqueólogos, SL: Actuación arqueológica..., cit. n. 3: 13-17. a cabo un desmantelamiento parcial de su pared septentrional (Fig. 5B) -cuyo deterioro ya se documentó en el momento de su descubrimiento (Benet et al., 1997: 453) - y de la cobertura del pasillo, puesto que, durante la excavación del relleno que lo colmataba, se hallaron varias planchas de pizarra de mediano y gran tamaño que podrían haber servido a modo de ortostatos delimitadores o 'lajas de cubierta'. En este sellado, se recuperaron abundantes materiales arqueológicos pertenecientes a objetos amortizados y depositados durante el acto de clausura (Fig. 8в): 43 puntas de flecha de distintas tipologías y materias primas -la mayoría con retoque plano bifacial-, 1 posible 'ficha' de cerámica, 1 cuenco casi completo decorado con triángulos incisos rellenos de puntos, 2 fragmentos cerámicos con puntos impresos, otros 2 con incisiones, 15 con motivos pintados en zigzag -probablemente pertenecientes a un mismo cuenco-y más de 300 restos de cerámica lisa 7 .

Las zonas de acceso también se encontraron clausuradas. En la entrada a la cámara se descubrió un gran bloque horizontal de cuarcita blanca -documentado y retirado en 1986-, que fue interpretado como la laja que habría servido a modo de dintel en el acceso al recinto cameral. Cabe la posibilidad de que este elemento arquitectónico fuese desmantelado y usado para bloquear la entrada a este espacio, como un acto más dentro del complejo ceremonial de clausura del monumento. Por su parte, en el tramo final del corredor y en la zona de acceso al monumento -campańas 1986 y 1989: niveles III y IV, cuadros E7 y E8; 1990: niveles II y III, cuadro E8; campaña 2005: $100-^{8}$, se registró una potente acumulación de grandes bloques de cuarcita dispuestos directamente sobre el sustrato natural (Fig. 9A), cubierta, a su vez, por una capa de cantos de río de pequeño y mediano tamaño (Fig. 9в), que bloqueaba dicho acceso por completo. Entre las piedras de este sellado, se depositaron de forma intencionada una gran cantidad de materiales, sobre todo cerámicas

\footnotetext{
Cf. Informe Técnico de Aratikos-Arqueólogos, SL: Actuación arqueológica..., cit. n. 3: 41-44 y Anexo 2a.

8 Cf. Informe Técnico de Aratikos-Arqueólogos, SL: Actuación arqueológica..., cit. n. 3: 24-31.
} 

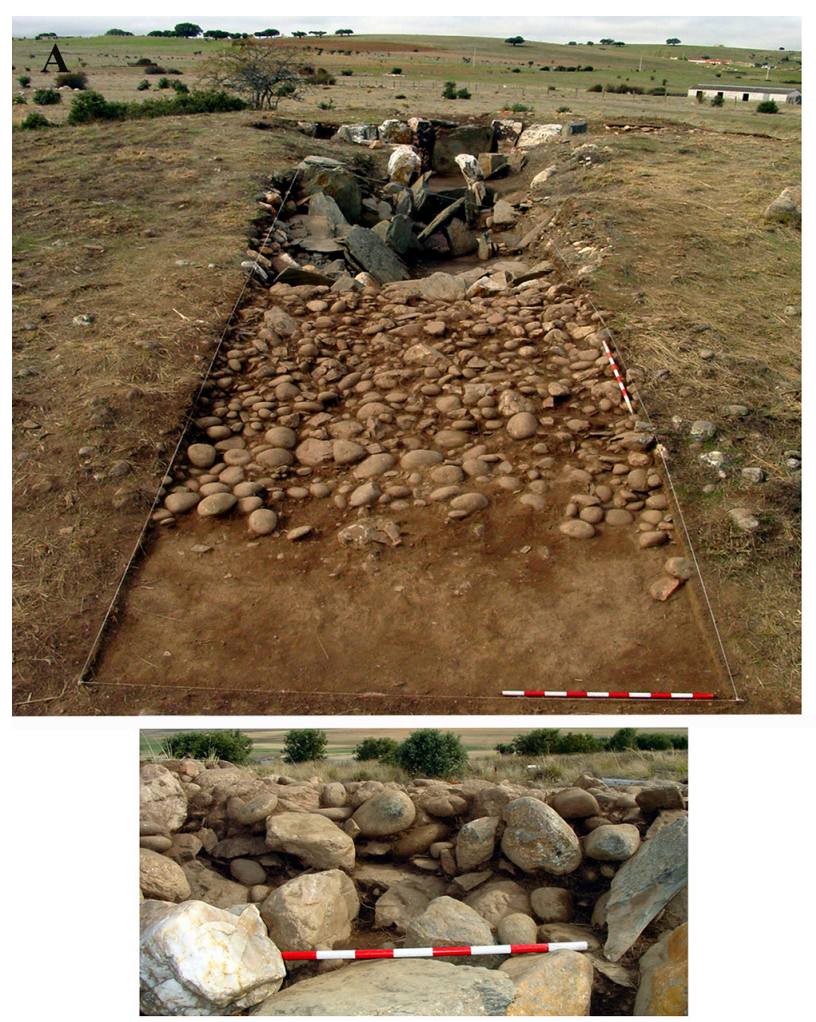
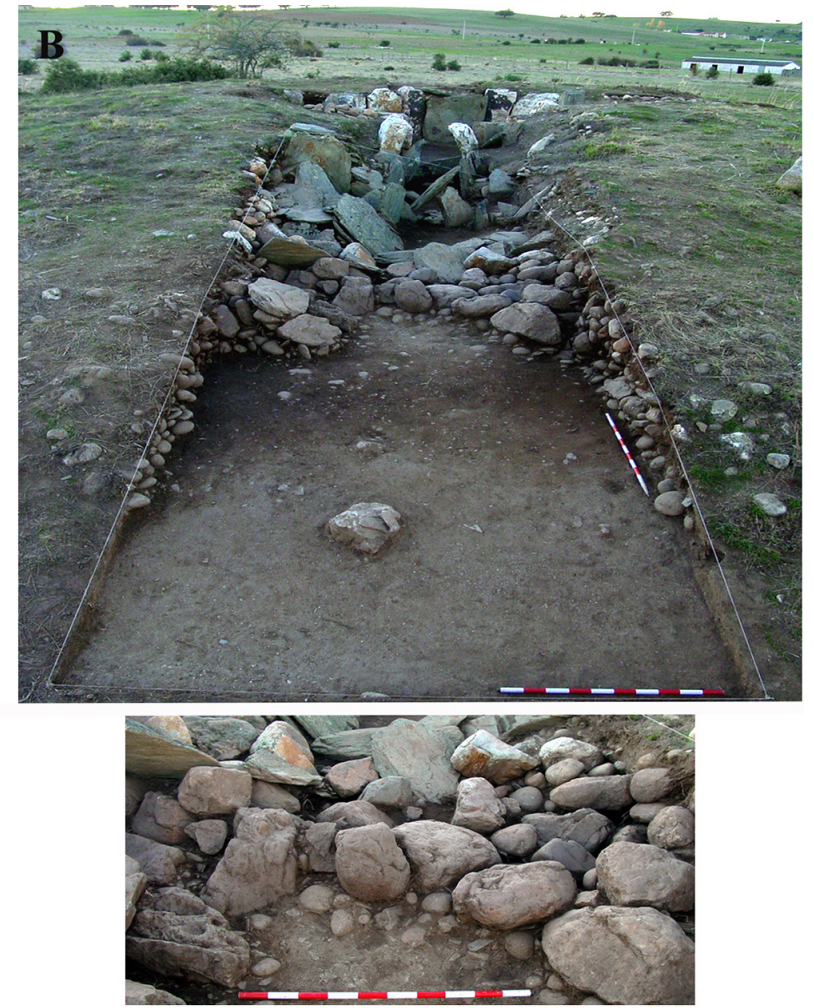

FIG. 9. Imagen general de El Teriñuelo: arriba, planta y sección del nivel superior y abajo, la estructura de clausura documentada en 2005.

(Fig. 10A) -en 2005 se recogieron 5.020 fragmentos cerámicos-9 ${ }^{9}$, a modo de ofrendas votivas arrojadas durante el desarrollo del ceremonial.

Se hallaron significativas acumulaciones de fragmentos, lisos en su mayoría, que pertenecían a recipientes que fueron amortizados tanto completos como semicompletos -es el caso de 1 cuenco decorado con triángulos rellenos de puntos, 1 olla lisa de cuello indicado, 4 cuencos o 1 ollita con perforaciones-. En algunas ocasiones, parece que las piezas fueron arrojadas in situ contra los bloques pétreos del sellado, dado que sus restos aparecieron dispersos pero en ubicaciones próximas -a unos 50 $\mathrm{cm}$ aproximadamente-. Esto fue lo que debió de ocurrir con 2 cuencos lisos -campaña 2005: recipientes 3 y 4 (Fig. 11) $-^{10}$ y con la mayoría de los

9 Cf. Informe Técnico de Aratikos-Arqueólogos, SL: Trabajos de excavación arqueológica..., cit. n. 3: 41.

$10 C f$. Informe Técnico de Aratikos-Arqueólogos, SL: Trabajos de excavación arqueológica..., cit. n. 3: 42-43. vasos decorados documentados: 2 cuencos con triángulos rellenos de puntos -2005: recipientes 1 y 2 (Fig. 11)-, 2 cuencos, 1 ollita y 1 vaso de almacenaje con decoración pintada y una ollita con triángulos incisos rellenos de puntos -estos últimos casos fueron catalogados en las campañas precedentes ${ }^{11}$. No obstante, la mayor parte de dichas acumulaciones cerámicas estaban constituidas por restos de distintos recipientes, rotos en otro lugar, y cuyos fragmentos fueron trasladados y depositados allí posteriormente, como una práctica más del ceremonial de clausura (Fig. 10B). Dentro de este último conjunto, se identificaron numerosas piezas decoradas: dos cerámicas con puntos impresos en el labio, otra con un cordón horizontal, un fragmento decorado con trazos impresos y otro con digitaciones -campaña 2005-, además de 157 piezas con

11 Cf. Informes Técnicos de Aratikos-ArqueóloGos, sL: Actuación arqueológica..., cit. n. 3: 42-44 y Anexo 2a y Trabajos de excavación arqueológica..., cit. n. 3: 41-43. 

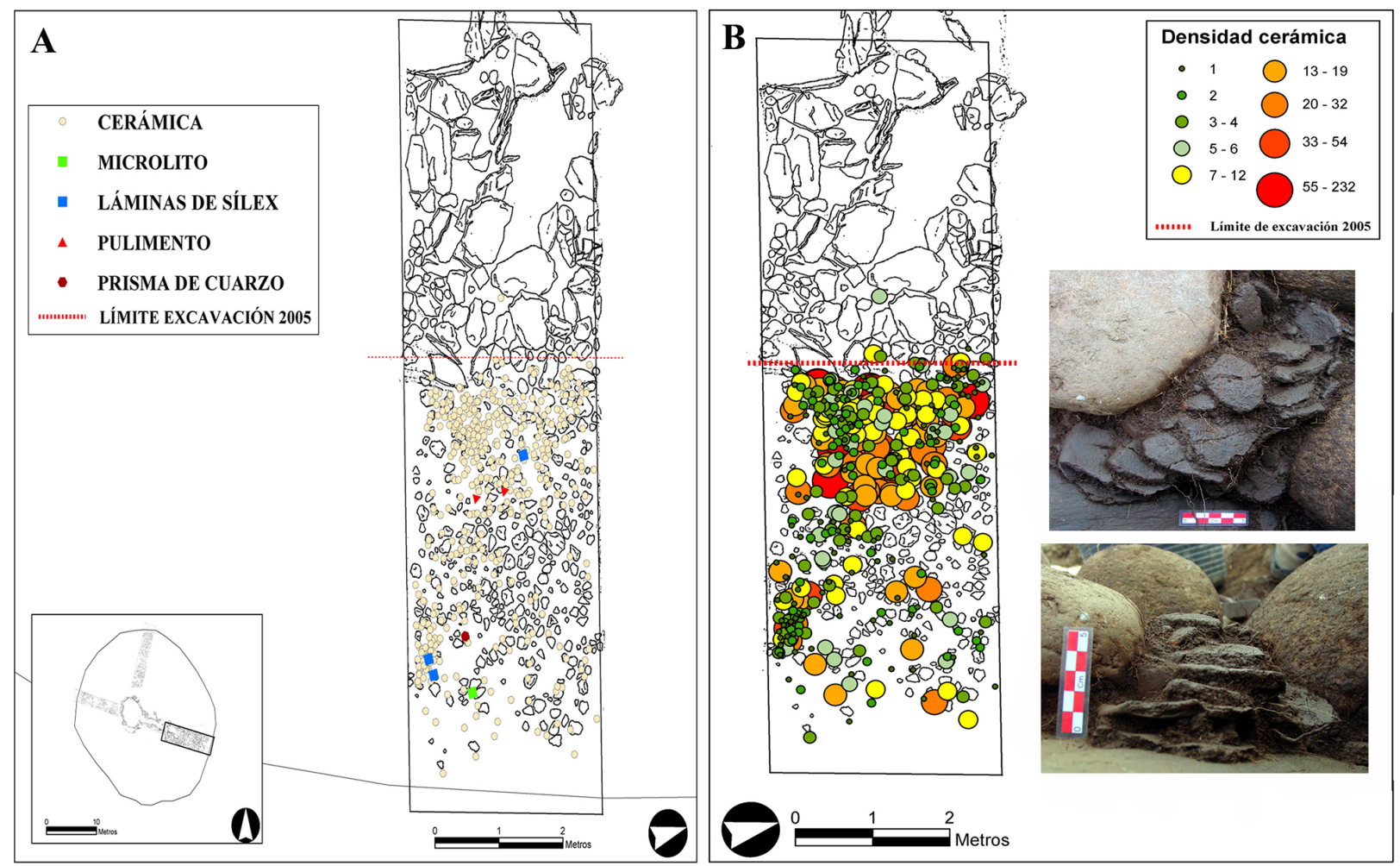

Fig. 10. Planos: A) de distribución de los materiales y B) de las densidades de fragmentos cerámicos hallados en la estructura de clausura; fotografías de algunas de las acumulaciones de cerámicas documentadas.

decoración pintada, 9 con incisiones, 2 con puntos impresos, otros 2 fragmentos con acanaladuras, 1 con puntos impresos y líneas incisas, 2 con decoración penteada y 1 con un motivo en espiga -intervenciones previas-. A todo este conjunto, hay que añadir las miles de cerámicas lisas pertenecientes a vasos de diferentes tipologías, cuyo número asciende a los 4.674 fragmentos -campańa de 2005- y a más de 7.000 -de anteriores excavaciones ${ }^{12}$. Dentro de esta colección cerámica (Fig. 8, fase II) predominan las formas hemiesféricas -cuencos de pequeño y mediano tamaño, ollas y ollitas de paredes entrantes- $y$, en menor medida, vasos de cuello indicado, de paredes rectas y de perfil en $s$, con la presencia anecdótica de una cazuelita carenada.

Otros materiales arqueológicos se hallaron también amortizados entre los bloques pétreos de la clausura: 16 puntas de flecha de diferente tipología

12 Ibidem. y con retoque plano bifacial, 2 núcleos de cuarzo, 11 láminas completas y varios fragmentos de otras -4 de estas piezas formaban 2 láminas completas que fueron fracturadas por flexión de manera intencional-, así como decenas de restos de talla y lascas de distintas materias primas (Fig. 10A). En este mismo contexto, se identificaron otros elementos que, por su tipología, estarían asociados a la primera 'etapa biográfica' y su hallazgo habría sido resultado de la alteración de los niveles originales y de su depósito azaroso entre las piedras del sellado, sin descartar la posibilidad de su amortización intencional como eventuales 'reliquias' u ofrendas votivas: 6 prismas de cuarzo, restos de ocre, 2 colgantes, 33 cuentas de collar -16 sobre piedra verde-, 2 fragmentos de pizarra, 13 hachas pulimentadas y 2 microlitos $^{13}$, a los que hay que añadir 1 prisma, 1 microlito, 1 hacha

13 Cf. Informe Técnico de Aratikos-Arqueólogos, sL: Actuación arqueológica..., cit. n. 3: 42-44 y Anexo 2a. 


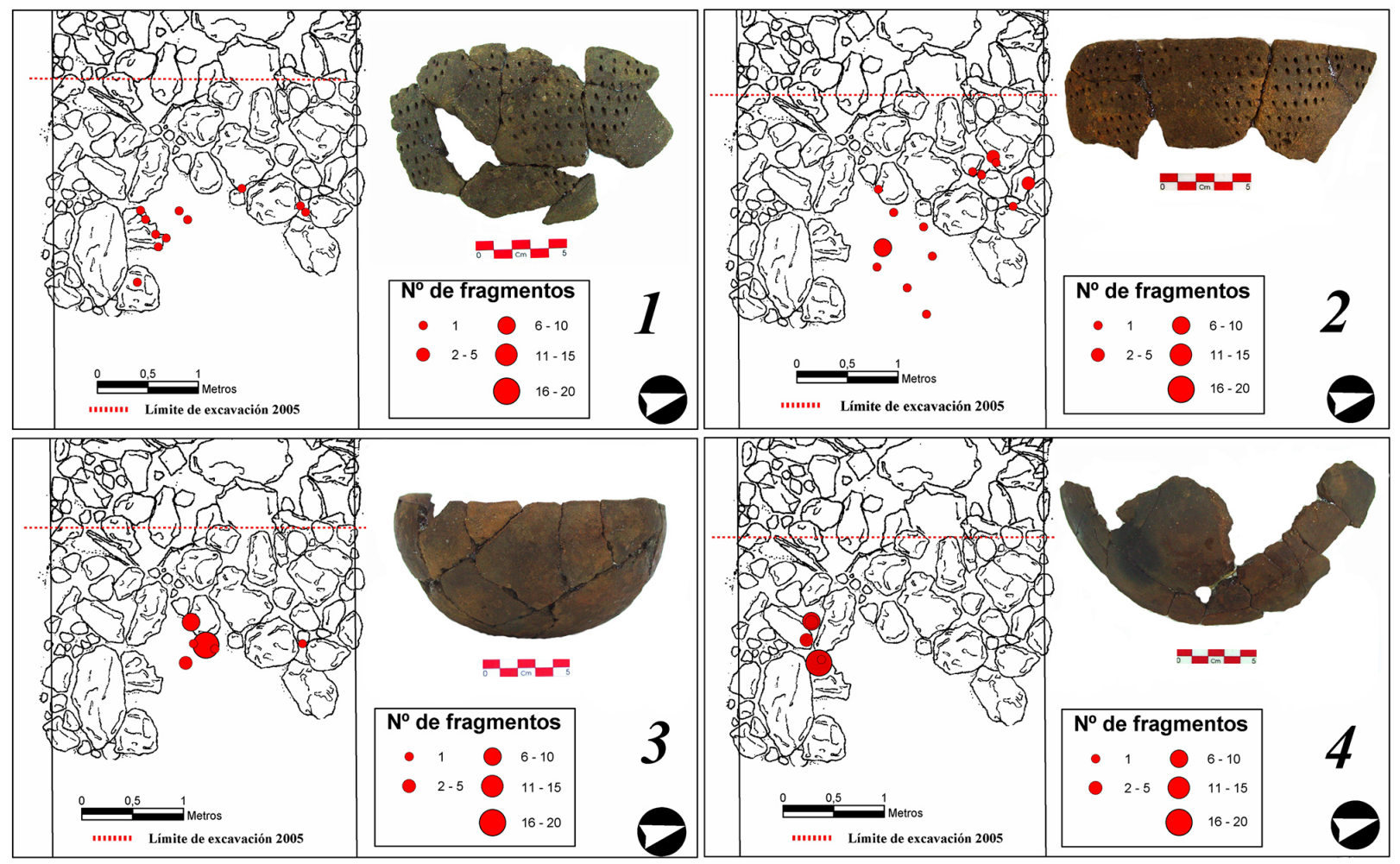

FIG. 11. Algunos de los recipientes cerámicos documentados en los niveles de sellado y plano de distribución de los respectivos fragmentos.

de factura tosca y 1 azuela pulimentada de cuidada elaboración, recuperados en la campaña de $2005^{14}$.

Esta práctica de clausura mediante la inhabilitación de las zonas de acceso al monumento se encuentra bastante extendida y bien documentada entre los megalitos de diversas regiones peninsulares (Alonso y Bello, 1997: 515-516; Mañana, 2003: 173; Delibes, 2004: 218-219; Narvarte, 2005: 307-310; García Sanjuán, 2005: 89-94; Prieto, 2007: 110; Tejedor, 2014: 78; etc.). Evidencias de este tipo se conocen en los corredores del Prado de la Nava (Benet et al., 1997: 453-454), La Ermita (Delibes y Santonja, 1986: 70-75) o Arroyal I en Burgos (Carmona et al., 2014: 48), en la entrada de los dólmenes de El Moreco y La Nava Negra, en la Lora burgalesa (Narvarte, 2005: 329; Delibes, 2010: 43), o en los atrios de las mamoas de Madorras I y Alagoas, en

14 Cf. Informe Técnico de Aratikos-Arqueólogos, SL: Trabajos de excavación arqueológica..., cit. n. 3: 40-41.
Trás-os-Montes (Huet y Cruz, 1994: 194-196; Sanches y Nunes, 2004: 8-18), entre otros. Estos actos rituales no se limitan sólo al ámbito megalítico, sino que se han identificado en contextos rito-funerarios diversos -hipogeos, cuevas sepulcrales, fosas o tholos megalíticos de cronología posterior (López de Calle e Ilarraza, 1997: 317; Bueno et al., 2005: 80; etc.)-, así como en lugares de hábitat -cierres y amortizaciones intencionales en hoyos- con cronologías del III milenio cal. вС.

Es importante destacar, dada su proximidad tanto geográfica como cronológica, la posible relación que pudo existir durante este episodio de uso entre El Terińuelo y el yacimiento de la Vińa de Esteban García que, como ya se ha mencionado, fue catalogado en principio como un posible dolmen (Delibes y Santonja, 1986: 106 y 108). Este asentamiento cuenta con dos dataciones radiocarbónicas sobre hueso que lo sitúan a lo largo del III milenio cal. BC 
(Delibes et al., 1997: 793-795): Beta-60885, 4120 \pm 90 вр, 2891-2479 cal. вС у Beta-60886, $3970 \pm$ 100 вр, 2761-2199 cal. вС (CalibRev 7.0.4., IntCal 13 , calibración a $2 \sigma)^{15}$. Se ubica a escasos $2 \mathrm{~km}$ al NE del dolmen, sobre un espolón de tierra que se mete en el embalse de Santa Teresa, una zona continuamente anegada salvo en épocas de sequía. Los materiales arqueológicos recuperados durante su excavación -más de 40.000 piezas- son, en muchos casos, similares a los asociados a esta Fase III: puntas de flecha, cerámicas de formas hemiesféricas, decoraciones pintadas, incisas e impresas, motivos ornamentales de triángulos rellenos de puntos, etc. (Delibes et al., 1997: 792-796) ${ }^{16}$. La hipótesis de la relación entre ambos yacimientos se apoya, también, en el hallazgo en dicho asentamiento de un fragmento de calota craneal y de parte de una mandíbula inferior humana ${ }^{17}$, lo que ha llevado a plantear la posibilidad de que las actividades desarrolladas en el dolmen en este momento tuvieran como protagonistas, al menos en parte, a los habitantes de este enclave ribereño del Tormes (Delibes et al., 1997: 804).

\subsection{Fase IV (segunda mitad del III milenio cal. BC): reutilización campaniforme}

El significativo conjunto de elementos asociados al 'fenómeno campaniforme' recuperado en El Teriñuelo ha permitido establecer una tercera 'etapa biográfica', que habría tenido lugar a lo largo de la segunda mitad del III milenio cal. BC.

C. Morán (1931: 54-59) fue quien realizó los hallazgos más espectaculares: 1 diadema y 1 cuenta de collar de oro, 1 puñal de lengüeta, 2 puntas de tipo Palmela, 2 punzones de cobre, 1 cazuelilla cerámica lisa y 2 fragmentos con decoración campaniforme -uno de 'estilo Marítimo', variedad MHV, y otro 'Ciempozuelos'-. Posteriormente, a esta colección se añadieron otra punta Palmela, 4 leznas y

15 Cf. Informe Técnico de Strato, cit. n. 2: Anexo I.

16 Cf. Informe Técnico de STrato, cit. n. 2: 119-149.

17 Cf. Informe Técnico de Strato, cit. n. 2: $121 \mathrm{y}$ 161, Anexo IV.
2 fragmentos indeterminados de cobre, 1 punta de sílex de pedúnculo y aletas y 5 plaquitas, 7 cuentas de collar y otros 7 apliques, todo ello en oro. También se recuperaron varias piezas con decoración campaniforme: 2 vasos de 'estilo Marítimo mixto-cordado' -variedad CZM-, 2 vasos y 1 cuenco de 'estilo Ciempozuelos' y 2 fragmentos sueltos - uno de 'estilo Marítimo' y otro 'Ciempozuelos'- (Benet et al., 1997: 450-453) ${ }^{18}$. En 2005 se registraron escasos materiales que, de forma inequívoca, puedan asociarse a esta fase de uso (Fig. 8, fase III), apenas 2 puntas de flecha de sílex de pedúnculo y aletas, 1 fragmento de 'estilo Marítimo' y varias piezas lisas pertenecientes a recipientes de distinta tipología, como vasos y cazuelillas ${ }^{19}$.

Todos estos elementos aparecieron dispersos y, en general, descontextualizados, principalmente en la cámara y a lo largo del corredor. Por el tipo de piezas catalogadas y la presencia de ciertos objetos singulares -como los adornos de oro, destacando, por su singularidad, la diadema-, su depósito podría estar vinculado a una ocupación funeraria. Tras el análisis de la distribución, posibles combinaciones y volumen de estos ajuares, algunos autores han planteado su posible correspondencia con uno o dos enterramientos en la cámara funeraria (Benet $e t$ al., 1997: 453): a uno de ellos estarían asociados los dos vasos decorados con variantes del "estilo Marítimo" y al otro, los recipientes de 'estilo Ciempozuelos'. Esta hipótesis viene avalada por las evidencias de actividad vinculada al 'fenómeno campaniforme' registradas en los dólmenes vecinos de El Teriñuelo de Salvatierra y el Prado de la Nava -donde se recuperó un numeroso conjunto de materiales, relacionado con hasta 3 o 4 posibles inhumaciones (Benet et al., 1997: 454)-, hallándose, en ambos casos, piezas con decoración de 'estilo Marítimo' muy similares a las documentadas en el dolmen estudiado. Más excepcional es el caso de La Ermita en Galisancho, en el que el análisis de la dispersión espacial de los elementos campaniformes ha llevado a plantear la

\footnotetext{
$18 C f$. Informe Técnico de Aratikos-Arqueólogos, SL: Actuación arqueológica..., cit. n. 3: 37-45 y Anexo 2a

19 Cf. Informe Técnico de Aratikos-Arqueólogos, SL: Trabajos de excavación arqueológica..., cit. n. 3: 39-40.
} 
existencia de un mínimo de 5 y un máximo de 8 depósitos, algunos muy probablemente de naturaleza funeraria (Delibes y Santonja, 1987: 185-186).

Sin embargo, la descontextualización del conjunto material descrito y la ausencia de restos humanos asociados al mismo no permiten afirmar, con total certeza, la naturaleza del evento que dio lugar a su depósito. Conviene señalar que la presencia en un mismo contexto de orfebrería áurea y de vajilla campaniforme no implica, necesariamente, que se trate de una tumba -como es el caso del túmulo soriano del El Alto III (Rojo et al., 2014: 33-34)-. De cualquier modo, con una finalidad, bien funeraria, bien votiva, los nuevos usuarios accedieron a un dolmen cuya entrada estaba sellada -afirmación basada, entre otros aspectos, en la ausencia de elementos campaniformes asociados directamente a los niveles intactos del sellado del corredor y de la zona de entrada-, por lo que, para poder acceder al interior, tuvieron que practicar algún tipo de desmantelamiento parcial de la estructura de cierre.

No se han documentado evidencias arqueológicas con la suficiente entidad como para definir una nueva ocupación posterior a esta tercera 'etapa biográfica’ en El Terińuelo, lo cual no quiere decir que no haya sido objeto de numerosas alteraciones a lo largo de su historia, que han afectado tanto a su contenido como a su propia estructura arquitectónica. Estos eventos intrusivos se han centrado en la cámara y en las capas más superficiales del corredor, donde los materiales aparecieron descontextualizados y mezclados con elementos modernos (Morán, 1931: 58). Tras las excavaciones de Morán, el recinto cameral fue reaprovechado como vertedero, hecho que alteró la disposición de parte de sus ortostatos e, incluso, se llegó a construir una pared de mampostería para cerrar por completo este espacio -en 1985 se desmanteló dicha construcción y se vació todo el relleno moderno-. Existen, además, testimonios orales que corroboran la destrucción de varias lajas del corredor en 1990, probablemente a consecuencia de las intrusiones clandestinas fomentadas por las leyendas de tesoros escondidos en este dolmen (Benet y Santonja, 1990: 281-282).

\section{El Terińuelo en su contexto social y ritual: continuidad y cambio desde una perspectiva 'biográfica'}

Los recurrentes eventos de reutilización en los monumentos megalíticos han sido interpretados, generalmente, desde dos perspectivas muy diferentes. Por una parte, hay autores que hablan de continuidad entre los distintos usuarios y sus respectivas estrategias socioeconómicas y rituales, defendiendo, de forma más o menos explícita, la ausencia de importantes transformaciones en las formas de vida y la organización social de las comunidades del interior peninsular entre el IV y el II milenio cal. BC (Delibes y Santonja, 1987: 191; Fabián, 1997: 95; Bueno et al., 2005: 70). Según esta hipótesis, la pervivencia del ritual funerario colectivo y el uso recurrente de un mismo lugar de enterramiento implican, necesariamente, la perduración y continuidad de las costumbres mortuorias ancestrales. Otros autores, por su parte, defienden que teniendo en cuenta los datos actualmente disponibles, en especial los cronológicos, no se puede hablar de "continuidad absoluta en el uso del monumento megalítico, en los ritos que en él pudieran tener lugar o, tampoco, en las características de la sociedad que los construye, utiliza, arregla y abandona” (Benet et al., 1997: 462). Siguiendo esta línea interpretativa, la ocupación recurrente de un espacio o la continuidad en el uso de una fórmula arquitectónica -el enterramiento bajo túmulo- no conlleva, necesariamente, la perduración de la misma ideología ni, mucho menos, del mismo orden socioeconómico que los originó.

El análisis 'biográfico' de los contextos megalíticos revela importantes transformaciones tanto en la forma como en el fin para el que fueron usados, así como en las propias prácticas que se desarrollaron en ellos, ya que “... tomar conciencia del 'tiempo largo' de los dólmenes como lugares sagrados no equivale a defender la invariabilidad absoluta de su significado ni de su mensaje originales"... (Delibes, 2004: 216). Las reutilizaciones de estos lugares se dieron en circunstancias completamente diferentes a las del momento de su construcción y primer uso. En este sentido, los megalitos habrían pervivido sin 
perder su importancia simbólica 'sagrada' ni su preeminencia en el paisaje (Delibes, 2004: 219), pero adoptando nuevos significados y funciones ligadas a su papel como instrumento de legitimación del poder, en un marco de lucha por la adquisición y el mantenimiento del liderazgo incipiente (Delibes et al., 1997: 805; Garrido, 2000: 55-58; Rojo et al., 2005: 17). Las modificaciones arquitectónicas documentadas en estos monumentos, tales como las remodelaciones, clausuras o reacondicionamientos, serían las manifestaciones más explícitas de la continua reinterpretación de estos espacios, por parte de las sociedades que coexistieron con ellos, y de su readaptación a las necesidades y requisitos de la ritualidad de cada momento. De ahí que sea necesario valorar el alcance interpretativo del estudio de las arquitecturas megalíticas y del análisis detallado de sus diferentes fases de construcción, reconstrucción y deconstrucción (Boujot, 2004), ya que, teniendo en cuenta que todas estas actuaciones habrían requerido de la participación colectiva y seguido unas pautas marcadas por el grupo, el descubrimiento de posibles patrones de comportamiento diferenciado a lo largo del tiempo podría desvelar cambios importantes en la esfera social.

Dentro del conjunto de las modificaciones arquitectónicas documentadas en monumentos megalíticos (Tejedor, 2014: 74-82), una de las más comunes es la de la 'clausura/sellado', cuyo resultado es el cese del uso 'canónico' del megalito, al inhabilitar, de forma definitiva, su espacio sepulcral o sus accesos. Son acciones voluntarias, que siguen una estrategia pautada y organizada en la que cada gesto tiene su tiempo y espacio de ejecución (Andrés, 2000: 71; Narvarte, 2005: 303-304). El término condamnation o 'condenación' suele utilizarse, a menudo, como sinónimo de este tipo de prácticas, dado que también se refiere a la secuencia de actos que dan lugar al cerramiento voluntario de un espacio sepulcral, dejándolo inutilizable e inaccesible (Le Roux, 2000: 269), pero careciendo de la carga simbólica y ceremonial que caracteriza a los sellados definitivos (Masset, 2002: 12). Además, algunos autores señalan que este término tiene una connotación negativa ligada a una intención

(c) Universidad de Salamanca de destruir el monumento o, incluso, de 'maldecirlo’ o 'castigarlo' (Andrés, 2000: 71). De ahí que, normalmente, se emplee 'clausura' como concepto para determinar aquellas actuaciones de naturaleza rito-ceremonial, cuyo único propósito es el de cerrar el megalito, sin intención de destruirlo. Por tanto, el acto de clausurar un monumento no conllevaría una ruptura total con el 'culto megalítico', sino que, simplemente, se trataría del fin de un ciclo, el funerario, y del inicio de una nueva etapa para el edificio como monumento conmemorativo y, quizás, como lugar de celebración y reunión. De esta forma, la clausura consistiría en una práctica necesaria y propia del 'ciclo biológico' de cualquier megalito, un 'rito de paso' que habrían de atravesar tras haber cumplido su función dentro de la comunidad (Narvarte, 2005: 352-361). Este hecho no implicaría el necesario abandono del lugar, como en ocasiones se ha defendido (Benet et al., 1997: 463; López de Calle e Ilarraza, 1997: 318-319; Delibes, 2004: 218-219), sino simplemente un cambio de funcionalidad. La imagen de la tumba colectiva sellada transmitiría un mensaje de eternidad y permanencia y se convertiría, además, en garante de la memoria colectiva y en 'emblema de la identidad del grupo’ (Andrés, 2010: 32). Por tanto, estos procesos de cierre que, en cierta medida, implicarían la destrucción de parte de la estructura arquitectónica, lejos de estar motivados por un deseo de romper con el entramado ideológico anterior, servirían como estrategias de perpetuación de los lazos con los antepasados y de refuerzo de la identidad colectiva (Delibes, 2010: 32). Cabe destacar que estos eventos de clausura aparecen muchas veces asociados a los denominados rituales de "cerámica matada o asesinada" (Prieto, 2007: 120), consistentes en la amortización in situ intencionada de uno o varios recipientes cerámicos. Este tipo de hallazgos podría estar ligado a prácticas de comensalidad (Garrido, 2000: 69; Thomas, 2005: 116-117; Delibes, 2010: 36), en las que se celebrarían banquetes ceremoniales con grandes cantidades de comida y bebida y en las que, posteriormente, la vajilla utilizada sería amortizada y sus restos incorporados, de manera simbólica, al monumento. 
En el dolmen de El Terińuelo, la estrategia de cierre elegida fue la colmatación deliberada de ciertas áreas como el corredor, la entrada al monumento o el acceso a la cámara, mediante la acumulación pautada, no caótica, de bloques pétreos de pequeño y mediano tamaño. Este acto conllevaría una intención evidente de inhabilitar su espacio interior, clausurando las potenciales zonas públicas de reunión y haciendo prácticamente imposible su continuidad como lugar ceremonial. La distribución de abundantes materiales de manera discontinua y localizada en determinados puntos de los niveles de sellado, así como su homogeneidad tipológica -fundamentalmente cerámicas, en su mayoría fragmentos lisos de pequeño y mediano tamaño-, indican que, lejos de tratarse de aportes accidentales junto con la tierra y los cantos usados para sellar el dolmen, fueron incorporados intencionadamente a modo de ofrendas rituales. El estudio analítico de estos materiales y de las circunstancias de su hallazgo ha permitido establecer tres tipos distintos de 'amortizaciones': algunos recipientes fueron depositados completos, otros más numerosos se rompieron in situ, pero sobre todo se realizaron acumulaciones de fragmentos de distintos recipientes, rotos en otro lugar y cuyos restos fueron, posteriormente, trasladados allí. Estas tres formas de depósito diferentes podrían estar vinculadas a diversas facetas del ceremonial de clausura. Siguiendo esta hipótesis, los recipientes completos y los que se rompieron in situ se corresponderían con las ofrendas depositadas por los individuos que participaron activamente en la ejecución de la clausura, quienes quizás tendrían alguna función específica dentro del ritual. Por su parte, los vasos que se rompieron en otro lugar, pero cuyos fragmentos también fueron incorporados al sellado, serían los utilizados por los asistentes a la ceremonia - probablemente miembros de varias comunidades vecinas- para, quizás, llevar a cabo libaciones u otras prácticas de comensalidad. De hecho, la mayor parte de los recipientes identificados son cuencos de pequeño y mediano tamaño que apenas superan el litro de capacidad y que, por tanto, se adecuarían perfectamente al consumo individual.

Este evento único y singular, que tuvo lugar en un momento concreto de la historia de El Terińuelo en el que sus usuarios decidieron clausurarlo, se caracterizó por el desarrollo de un complejo ceremonial de gran carga simbólica y social, que implicó no sólo el bloqueo del corredor y de la entrada al dolmen, sino también del acceso a la cámara. Sin embargo, con este acto de clausura no concluyó su 'biografía', puesto que, como se ha expuesto a lo largo de este artículo, nuevos episodios de uso posteriores han ido completando una larga vida de ritos, ceremonias y discursos en torno a este monumento ancestral que, aún, reclama los nuestros.

\section{Bibliografía}

Alonso, F. y Bello, J. M. (1997): "Cronología y periodización del fenómeno megalítico en Galicia a la luz de las dataciones por Carbono 14". En Rodríguez Casal, A. (ed.): $O$ Neolítico atlántico e as orixes do Megalitismo. Santiago de Compostela, pp. 507-520.

Andrés, T. (2000): "El espacio funerario dolménico: abandono y clausura”, Salduie, 1, pp. 59-76.

AndrÉs, T. (2010): "Identificando la identidad en la prehistoria, por la Prehistoria”, Salduie, 10, pp. 1343.

Benet, N.; Pérez, R. y Santonja, M. (1997): "Evidencias campaniformes en el valle medio del Tormes". En Balbín, R. y Bueno, P. (coords.): II CAP: Neolítico, Calcolítico y Bronce (Zamora, 1996). Zamora: FRAH, vol. 2, pp. 449-470.

Benet, N. y Santonja, M. (1990): "Salamanca", Numantia, III, pp. 281-292.

Boujot, C. (2004): "Entre masse inerte et vecteur dynamique de production d'espace: quelles perspectives pour l'étude des architectures funéraires mégalithiques dans l'approche des sociétés néolithiques". En Baray, L. (coord.): Archéologie des pratiques funéraires: approches critiques. Actes Table Ronde de l'UMR $5594 d u$ CNRS (Bibracte, 2001). Glux-en-Glenne: Centre Archéolog. Européen du Mont Beuvay, pp. 249-254.

Bradley, R. (1993): Altering the earth. The origins of monuments in Britain and continental Europe. Monograph Series, 8. Edinburgh: Society of Antiquaries of Scotland.

Bradley, R. y Williams, H. (eds.) (1998): The past in the past. The reuse of ancient monuments. World Archaeology, 30 (1). London: Routledge. 
Bueno, P. (1991): Megalitos en la Meseta Sur: los dólmenes de Azután y La Estrella (Toledo). Excavaciones Arqueológicas en España, 159. Madrid.

Bueno, P.; Barroso, R. y Balbín, R. de (2005): "Ritual campaniforme, ritual colectivo: la necrópolis de cuevas artificiales del Valle de las Higueras, Huecas, Toledo", Trabajos de Prehistoria, 62 (2), pp. 67-90.

Carmona, E.; Arnáiz, M. A. y Alameda, M. ${ }^{a}$ C. (2014): "El dolmen de Arroyal I: usos y modificaciones durante el III milenio ac". En Honrado, J.; Brezmes, M.; Tejeiro, A. y Rodríguez MonteRRUBIO, O. (coords.): Investigaciones Arqueológicas en el valle del Duero: Del Neolitico a la Antigüedad Tardía. II Jornadas Jóvenes Investigadores del Valle del Duero. Valladolid: Ed. Glyphos, pp. 41-54.

Cruz, D. (1995): "Cronologia dos monumentos com tumulus do noroeste peninsular e da Beira Alta”, Estudos Pré-históricos, 3, pp. 81-119.

Delibes, G. (2004): "La impronta Cogotas i en los dólmenes del occidente de la cuenca del Duero o el mensaje megalíticos renovado", Mainake, 26, pp. 211-231.

Delibes, G. (2010): "La investigación de las sepulturas colectivas monumentales del IV milenio a.C. en la Submeseta Norte española. Horizonte 2007”. En Fernández, J. y Mujika, J. A. (eds.): Actas Congreso Intern. sobre Megalitismo y otras manifestaciones funerarias contemporáneas en su contexto social, económico y cultural (Beasain, 2007). Munibe Supl. 32. San Sebastián: Soc. Ciencias Aranzadi, pp. 13-56.

Delibes, G.; Benet, N.; Pérez Martín, R. y Zapatero, P. (1997): "De la tumba dolménica como referente territorial, al poblado estable: notas sobre el hábitat y las formas de vida de las comunidades megalíticas de la Submeseta Norte". En Rodríguez Casal, A. (ed.): O Neolítico Atlántico e as orixes do Megalitismo. Actas Coloquio Internacional (Santiago de Compostela, 1996). Santiago de Compostela, pp. 779-808.

Delibes, G. y Rojo, M. (1988): "En torno al origen del foco megalítico del oriente de la Meseta: de nuevo el sepulcro de Cubillejo de Lara", Bol. Seminario Arte y Arqueologia, 54, pp. 5-23.

Delibes, G. y Rojo, M. (2002): "Reflexiones sobre el trasfondo cultural del polimorfismo megalítico en la Lora burgalesa", Archivo Español de Arqueología, Lxxv, pp. 21-35.

Delibes, G.; Rojo, M. y Sanz Mínguez, C. (1986): "Dólmenes de Sedano II. El sepulcro de corredor de Las Arnillas (Moradillo de Sedano, Burgos)", Noticiario Arqueológico Hispánico, 27, pp. 9-39.
Delibes, G. y Santonja, M. (1986): El fenómeno megalítico en la provincia de Salamanca. Serie Prehistoria y Arqueología, 1. Salamanca: Ed. Diputación de Salamanca.

Delibes, G. y Santonja, M. (1987): "Sobre la supuesta dualidad Megalitismo/Campaniforme en la Meseta Superior Española”. En Waldren, W. y Kennard, R. C. (eds.): Bell Beakers of the Western Mediterranean. Definition, Interpretation, Theory and new site Data. The Oxford International Conference, 1986. BAR Intern. Ser., 331 (I). Oxford: Archaeopress, pp. 173-206.

Fabián, J. F. (1997): El Dolmen del Prado de las Cruces (Bernuy-Salinero, Ávila). Serie Monografías, 5. Valladolid: JCyL.

García SANJuÁN, L. (2005): "Las piedras de la memoria. La permanencia del Megalitismo en el suroeste de la Península Ibérica durante el II y I milenios ANE", Trabajos de Prehistoria, 62 (1), pp. 85-109.

Garrido, R. (2000): El Campaniforme en la Meseta central de la Peninsula ibérica (c. 2500-2000 A.C.). BAR Intern. Ser., 892. Oxford: Archaeopress.

Guy, H. y Masset, C. (1991): "Procédure de condamnation d'une allée couverte Seine-Oise-Marne (Méréaucourt, Somme)", Bulletin de la SPF, 88 (9), pp. 282-288.

Hingley, R. (1996): "Ancestors and identity in the later prehistory of Atlantic Scotland: the reuse and reinvention of Neolithic monuments and material culture", World Archaeology, 28 (2), pp. 231-243.

Holtorf, C. (2000-2008): Monumental Past: The Life-histories of Megalithic Monuments in Mecklenburg-Vorpommern (Germany). Electronic monograph. University of Toronto: Centre for Instructional Technology Development (https://tspace. library.utoronto.ca/citd/holtorf/0.1.html [acceso: 08/02/2016]).

Huet, A. y Cruz, D. (1994): "Resultados dos trabalhos de escavação da mamoa 1 de Madorras (S. Lourenço de Ribapinhão, Sabrosa, Vila Real)". En O Megalitismo no Centro de Portugal: novos dados, problemática e relaçôes com outras áreas peninsulares (Mangualde, 1992). Estudos Pré-Históricos, 2. Viseu: Cepba, pp. 171-232.

Jorge, V. O. (1983-1984): "Megalitismo do Norte de Portugal: um novo balanço", Portugália, 4/5, pp. 37-45.

Jorge, V. O. (1987): "Megalitismo de Entre-Douro-e-Minho e de Trás-os-Montes (Norte de Portugal): conhecimentos actuais e linhas de pesquisa a desenvolver". En El Megalitismo en la Peninsula Ibérica. Madrid: Ministerio de Cultura, pp. 111-125. 
Kalb, P. (1987): "Monumentos megalíticos entre Tejo e Douro". En El Megalitismo en la Peninsula Ibérica. Madrid: Ministerio de Cultura, pp. 95-109.

Le Roux, C. T. (2000): "Il faut qu'une tombe soit ouverte ou fermée". En GonçAlves, V. (ed.): Muitas antas, pouca gente? I Colóquio Internacional sobre Megalitismo (Reguengos de Monsaraz, 1996). Trabalhos de Arqueologia, 16. Lisboa: IPpar, pp. 267-282.

LeClerc, J. y MASSET, C. (1980): “Construction, remaniements et condamnation d'une sepulture collective néolithique: La Chausée-Tirancourt (Somme)", Bulletin de la SPF, 77 (2), pp. 57-64.

LeClerc, J. y Masset, C. (1987): "Recherche de critères fonctionnels, en vue d'une typologie des sepultures collectives néolithiques". En Compte-rendu de la Table Ronde tenue à Saint-Germain (Laye, 1987). Paris: CNRS, pp. 54-56.

López de Calle, C. e Ilarraza, J. A. (1997): “Condenaciones y remodelaciones. Una respuesta a las estratigrafías de los sepulcros megalíticos de Cameros". En Balbín, R. y Bueno, P. (coords.): II CaP: Neolitico, Calcolítico y Bronce (Zamora, 1996). Zamora: FRAH, vol. 2, pp. 309-322.

López Plaza, S. (1982): Aspectos arquitectónicos de los sepulcros megalíticos de las provincias de Salamanca y Zamora. Salamanca: Univ. de Salamanca.

López Plaza, S.; López Plaza, M. y López Moro, F. J. (2008): "Factores litológicos como indicadores del paisaje en el megalitismo de la penillanura salmantina (centro-oeste de España)", Zephyrus, LXI, pp. 107-130.

López Plaza, S.; Luis Francisco, J. y Salvador, R. (2000): "Megalitismo y vías naturales de comunicación en el so salmantino". En Jorge, V. O. (coord.): III CAP Neolitização e Megalitismo da Península Ibérica (Vila Real, 1999). Porto: AdeCAP, vol. 3, pp. 271-287.

Maluquer de Motes, J. (1956): Carta arqueológica de España, Salamanca. Salamanca: Diput. Prov. de Salamanca.

Mañana, P. (2003): "Vida y muerte de los megalitos. ¿Se abandonan los túmulos?”, Era Arqueología, 5, pp. 164-177.

Mañana, P. (2005): "Túmulo 5 de Forno dos Mouros (Ortigueira, A Coruńa). Primeiros resultados", Cuadernos de Estudios Gallegos, 52 (118), pp. 39-79.

Masset, C. (2002): "Ce qu'on sait, ou croit savoir, du rôle du feu les sépultures collectives néolithiques". En Rojo, M. y Kunst, M. (eds.): Sobre el significado del fuego en los rituales funerarios del Neolítico. Studia Archaeologica, 91. Valladolid: Univ. de Valladolid, pp. 9-20.
Morán, C. (1931): Excavaciones en dólmenes de Salamanca. Memoria n. ${ }^{\circ}$ 113. Madrid: Junta Superior del Tesoro Artístico.

Narvarte, N. (2005): Gestión funeraria dolménica en la cuenca alta y media del Ebro: fases de ocupación y clausura. Historia-Arqueología, 16. Logroño: IER.

Prieto, P. (2007): "Volviendo a un mismo lugar: recipientes y espacios en un monumento megalítico gallego", Revista Portuguesa de Arqueologia, 10 (2), pp. 101-125.

Rogers, A. (2013): "The afterlife of monuments in the English peak district: the evidence of early Bronze Age burials", Oxford Journal of Archaeology, 32 (1), pp. 39-51.

Rojo, M. (2014): "El Neolítico en las tierras del interior y septentrionales". En Almagro Gorbea, M. (ed.): Protohistoria en la Península Ibérica: del Neolítico a la Romanización. Burgos: Univ. de Burgos-Fund. Atapuerca, pp. 43-70.

Rojo, M.; Garrido, R.; García, I. y Tejedor, C. (2013): "Lithology and colour in the symbolic landscape of megalithic tombs in the Ambrona Valley (Soria, Spain)". En Guyodo, J. N. y Mens, E. (eds.): Les premières architectures en pierre en Europe occidentale $d u v$ au II millénaire avant J.-C. Rennes: PUR, pp. 211-219.

Rojo, M.; Garrido, R.; García, I. y Tejedor, C. (2014): "Beaker Barrows (not) for the dead: El Alto I \& III, Las Cuevas/El Morrón and La Perica (Soria, Spain)", CUPAUAM, 40, pp. 31-40.

Rojo, M.; Garrido, R.; Morán, G.; García, I. y Kunst, M. (2005): "Del enterramiento colectivo a la tumba individual: el sepulcro monumental de La Sima en Miño de Medinaceli, Soria, España”, Bol. Seminario Arte y Arqueología, 72-73, pp. 7-38.

Rojo, M.; Garrido, R.; Tejedor, C.; García, I.; Alt, K. y Zesch, S. (2015): "El tiempo y los ritos de los antepasados. La Mina y El Alto del Reinoso, novedades sobre el Megalitismo en la cuenca del Duero". En Homenaje a R. de Balbin Behrmann, ARPI, 3, pp. 133-147.

Rojo, M; Kunst, M.; Garrido, R.; García, I. y MoRÁN, G. (2005): Un desafío a la eternidad. Tumbas monumentales del Valle de Ambrona. Arqueología en Castilla y León, 14. Valladolid: JCyL.

Sanches, M. ${ }^{a}$ J. y Nunes, S. A. (2004): "Resultados da escavação da Mamoa D’Alagoa (Toubres-Jou)Murça (Trás-os-Montes)", Portugália, 25, pp. 5-42.

Sanches, M. ${ }^{a}$ J.; Nunes, S. A. y Silva, M. S. (2005): "A Mamoa 1 do Castelo (Jou)-Murça (Trás-osMontes): resultados dos trabalhos de escavaçáo e de 
restauro dum Dólmen de Vestíbulo", Portugália, 26, pp. 5-39.

Santonja, M. (1987): "Anotaciones en torno al Megalitismo del Occidente de la Meseta (Salamanca y Zamora)". En El Megalitismo en la Peninsula Ibérica. Madrid: Min. de Cultura, pp. 199-210.

Santonja, M. (1997): "Los tiempos prehistóricos". En Martín Rodríguez, J. L. (coord.): Historia de Salamanca. Vol. 1. Prehistoria y Edad Antigua. Salamanca: CES, pp. 17-122.

Santonja, M.; Benet, N.; Frades, M. ${ }^{a}$ J. y García Martín, J. (1996): "El dolmen de El Teriñuelo (Salvatierra de Tormes). Actualización del inventario dolménico salmantino", Salamanca. Revista de Estudios, 37, pp. 13-28.

Tejedor, C. (2014): "Reconstruyendo 'biografías megalíticas': algunos ejemplos de alteraciones estructurales en monumentos megalíticos del valle del Duero/Douro". En Honrado, J.; Brezmes, M.; Tejeiro, A. y Rodríguez Monterrubio, O. (coords.):
Investigaciones Arqueológicas en el valle del Duero: Del Neolítico a la Antigüedad Tardía. II Jornadas de Jóvenes Investigadores del valle del Duero. Valladolid: Ed. Glyphos, pp. 67-86.

Thomas, J. (2005): “¿Ceremonias de los jinetes?: de las tumbas megalíticas a los enterramientos campaniformes en la Europa prehistórica”. En Rojo, M.; GARRIDO, R. y García, I. (coords.): El Campaniforme en la Peninsula Ibérica y su contexto europeo. Serie de Arte y Arqueología, 21. Valladolid: Univ. de Valladolid, pp. 107-119.

Villalobos, R. (2014): "The megalithic tombs of the Spanish Northern Meseta. Material, political and ideological ties between the Neolithic people and their territory". En Robin, G.; D'Anna, A.; Schmitt, A. y Bailly, M.: Préhistoires Méditerranéennes. Colloque Fonctions, utilisations et représentations de l'espace dans les sépultures monumentales $d u$ Néolithique européen (http://pm.revues.org/104703 [acceso 03/01/2015]). 
